This item was submitted to Loughborough's Research Repository by the author.

Items in Figshare are protected by copyright, with all rights reserved, unless otherwise indicated.

\title{
Multi-scale damage modelling of 3D woven composites under uni-axial tension
}

PLEASE CITE THE PUBLISHED VERSION

http://dx.doi.org/10.1016/j.compstruct.2016.01.103

PUBLISHER

(C) Elsevier Ltd.

VERSION

AM (Accepted Manuscript)

\section{PUBLISHER STATEMENT}

This work is made available according to the conditions of the Creative Commons Attribution-NonCommercialNoDerivatives 4.0 International (CC BY-NC-ND 4.0) licence. Full details of this licence are available at: https://creativecommons.org/licenses/by-nc-nd/4.0/

\section{LICENCE}

CC BY-NC-ND 4.0

\section{REPOSITORY RECORD}

Dai, Shuo, and Paul Cunningham. 2016. "Multi-scale Damage Modelling of 3D Woven Composites Under Uniaxial Tension". figshare. https://hdl.handle.net/2134/20452. 


\section{Accepted Manuscript}

Multi-scale damage modelling of 3D woven composites under uni-axial tension

S. Dai, P.R. Cunningham

PII:

S0263-8223(16)30015-0

DOI: http://dx.doi.org/10.1016/j.compstruct.2016.01.103

Reference: COST 7209

To appear in:

Composite Structures

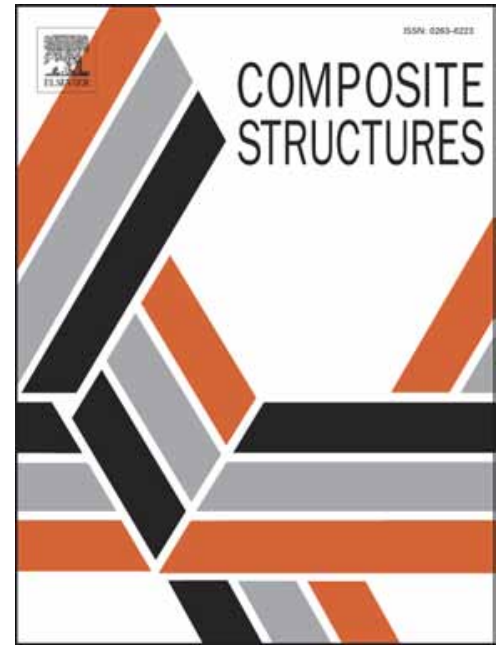

Please cite this article as: Dai, S., Cunningham, P.R., Multi-scale damage modelling of 3D woven composites under uni-axial tension, Composite Structures (2016), doi: http://dx.doi.org/10.1016/j.compstruct.2016.01.103

This is a PDF file of an unedited manuscript that has been accepted for publication. As a service to our customers we are providing this early version of the manuscript. The manuscript will undergo copyediting, typesetting, and review of the resulting proof before it is published in its final form. Please note that during the production process errors may be discovered which could affect the content, and all legal disclaimers that apply to the journal pertain. 


\title{
Multi-scale damage modelling of 3D woven composites under uni-axial tension
}

\author{
S. Dai ${ }^{\mathrm{a}, *}$, P. R. Cunningham ${ }^{\mathrm{a}}$ \\ ${ }^{a}$ Department of Aeronautical and Automotive Engineering, School of Aeronautical, Automotive, Chemical and \\ Materials Engineering, Loughborough University, LE11 3TU, UK.
}

\begin{abstract}
This paper presents a detailed numerical analysis of two types of 3D woven composite architecture. a unit cell, full finite element meso model, and a mosaic macro model are developed to simulate the elastic and damage progression behaviour of the two weave types. Both models predicted the tensile modulus and strength within $20 \%$ of the experimentally measured values, and the predicted failure sequence was similar to the experimental observation.
\end{abstract}

Keywords: 3D woven composites; Unit cell; Multi-scale modelling; Damage modelling.

\section{Introduction}

Three dimensional (3D) woven composites offer the potential for lower cost high volume manufacturing processes and higher out-of-plane mechanical properties compared to traditional laminated composites. However, several problems arise with 3D woven composites. Voids and resin rich pockets are more likely to occur due to the liquid resin transfer moulding process, the in-plane mechanical properties can be degraded due to the presence of crimps induced by the weaving process, and predicting the mechanical properties is also complicated by the complex reinforcement structure. Several modelling techniques have been developed in the literature, such as the unit cell model, mosaic model, and binary model.

The unit cell model is the most widely used approach to simulate the mechanical behaviour of the $3 \mathrm{D}$ woven composites. Since the $3 \mathrm{D}$ woven composite is generally constructed by repeating identical unit cells, its behaviour can be simulated by modelling a unit cell with periodical boundary conditions [1]. The unit cell is mostly modelled as a block with the tow following idealised [2] or realistic paths $[3,4]$ and its constant [2] or variable [3, 4] cross-section being elliptical $[5,6,7]$, rectangular [6], or lenticular [7]. Once the unit cell is built, load or displacement is then applied to the unit cell and the behaviour can be then simulated using Finite Element Analysis or analytical methods. Both tensile $[2,8]$ and compressive $[9,10]$ properties have been predicted successfully. Maximum stress was one of the popular criterion to define failure $[2,4,8]$, and different failure modes (such as longitudinal tensile failure and transverse tensile failure) have been predicted showing good agreement with the experimental data [4].

\footnotetext{
${ }^{*}$ Corresponding author. Email: ShuoDai@outlook.com
} 
The Mosaic model and binary model were developed for multi-scale simulation. In the mosaic model, the composite structure was discretised into a mosaic assemblage with each mosaic brick element having distinct material properties. Global displacement or stress can be applied to the macro level model and then transferred to the mosaic blocks using iso-stress or iso-strain conditions [11]. The mosaic model has been used to predict both elastic and strength properties for both flat samples and T-section stiffeners $[12,13,14]$. However, this model faces the challenges of internal continuity and stress singularity problems, which is caused by the two adjacent mosaic blocks having distinctive elastic properties.

The binary model is also capable of predicting the behaviour of structural component such as stiffeners [15]. Both the elastic and damage behaviour of 3D fabric structures have been simulated and showed good agreement with experiments [16, 17, 18]. The Binary Model is a more computational efficient model than any other direct 3D FE models, and it offers a relatively easier way to incorporate non-linear properties into the model. However, since only one-dimensional elements are used to model tows, the shear and transverse stress transfer between the resin and tow cannot be easily modelled.

In order to investigate the effect of different failure criteria and simulate large scale structures, two numerical models at different scale levels were created to simulate the damage behaviour of 3D woven composites. A meso-scale unit cell model was created to simulate the detailed damage development during tensile loading using different failure criteria. Once the damage modelling technique was verified through the unit cell model, a mosaic model was developed to predict the notched tensile properties and the stress distribution in a macro-scale level.

\section{Modelling strategies}

Two types of 3D woven composite have been modelled: an orthogonal weave $\mathrm{W}-1$ and an angle interlock weave W-3 as shown in Figure 1. Both weaves were manufactured using a traditional narrow fabric weaving loom by M. Wright \& Sons Ltd. Detailed geometrical and mechanical properties of these composites have been published in [19].

\subsection{Model geometry}

\subsubsection{Unit cell model}

The unit cell was built in Abaqus 6.11 with each tow modelled as a transversely isotropic homogeneous composite material and the matrix modelled as an isotropic epoxy resin. Due to the complexity of the woven geometry, tetrahedral elements with four nodes (C3D4) were used. Each tow was created by partitioning the unit cell block so that it shared the nodes with the resin elements. Based on the microscopic images, the waviness of the warp and weft tows were relatively low [19]. Therefore the warp and weft tows were modelled as idealised non-crimp unidirectional (UD) composites, and the binder tows were also modelled as UD composites with the local fibre orientation following the swept path. The intra-tow fibre volume fraction (packing factor) was back-calculated from the geometry of the unit cell and the experimental fibre volume fraction so that the $V_{f}$ was the same in the models and the samples as listed in Table 2. The dimensions of the tows are listed in Table 3 and the intra-yarn packing factors $\left(V_{p f}\right)$ are listed in Table 5 . To avoid interpenetration and 
skewed elements around the contact region, a thin layer of matrix $(0.005 \mathrm{~mm})$ existed between every two adjacent tows [20]. Since the unit cell is symmetrical and the periodical boundary condition requires a symmetrically surface mesh, only a quarter of the unit cell was built and meshed in Abaqus as shown in Figure 2. A Matlab program was written to produce the whole unit cell from the quarter cell, and to apply a node-to-node based periodical boundary condition developed by S. Li [1]. Displacement was applied to the unit cell via the periodical boundary condition and Abaqus Explicit solver and a VUMAT code within Abaqus was used to compute the deformation of the unit cell.

The Young's modulus and the tensile strength of the W-1 unit cell model with different mesh sizes were plotted in Figure 4. As can be seen the modulus converged in models with more than 40000 elements and the difference between the highest and the lowest modulus in the converged models was less than $1 \%$. The strength varied slightly among the six models but the variation was $38 \mathrm{MPa}$ which is less than $2.5 \%$. The longitudinal stress along a warp tow (illustrated in Figure 5 ) was plotted at 4400 micro-strain when damage (matrix cracking) initiated. The stress distribution in all six sized models showed similar trend along the length of the warp tow and the value of the concentrated stress converged after refining the mesh to $0.24 \mathrm{~mm}$. The difference between the maximum stresses in the converged models was about $1 \%$. Therefore the solution was considered to be converged with a nominal mesh size of $0.24 \mathrm{~mm}$ which were used for all of the models in this study.

\subsubsection{Mosaic model}

The macro-scale model was built by assembling a number of mosaic unit cells (created in Abaqus) into a sample scale model using a Matlab code, which was then simulated under deformation using Abaqus Explicit. As shown in Figure 3, each unit cell was discretised into several C3D8 (eight noded) brick elements of different material, and the binder tow showed a stepwise path due to this voxel type of discretisation. Each tow was modelled as a unidirectional CFRP composite material. The model was first created as a rectangular shaped $48 \mathrm{~mm}$ long (warp direction) and $25 \mathrm{~mm}$ wide (weft direction) sample and was then modified to an open-hole sample by deleting the extra elements and changing the node coordinates. No periodical boundary condition was required in the mosaic model since it simulates the whole sample. Longitudinal displacement was applied to one surface perpendicular to the $\mathrm{x}$-axis until final failure, and zero-displacement boundary conditions were applied to the opposite surface as shown in Figure 3. The damage process was modelled using the same element deletion technique as the unit cell model, and the same Maximum Stress failure criterion was used to define damage due to its simplicity and adequate accuracy. Both the elastic and strength models were built to simulate the tensile behaviour of both un-notched and open-hole samples, and the results are discussed in the following sections.

\subsection{Failure criteria}

The elastic properties were calculated using the Chamis rules [21] as listed in Equation 1. Table 4 lists the raw material properties which were obtained from the manufacturer's data sheets, previous publications [22, 23], and online resources [24]. 


$$
\begin{gathered}
E_{1}=E_{1 f} V_{p f}+E_{m}\left(1-V_{p f}\right) \\
E_{2}=E_{3}=\frac{E_{m}}{1-\sqrt{V_{p f}}\left(1-E_{m} / E_{2 f}\right)} \\
G_{12}=G_{13}=\frac{G_{m}}{1-\sqrt{V_{p f}}\left(1-G_{m} / G_{12 f}\right)} \\
G_{23}=\frac{G_{m}}{1-\sqrt{V_{p f}}\left(1-G_{m} / G_{23 f}\right)} \\
\nu_{12}=\nu_{13}=\nu_{12 f} V_{p f}+\nu_{m}\left(1-V_{p f}\right) \\
\nu_{23}=\frac{E_{22}}{2 G_{23}}-1
\end{gathered}
$$

Since each tow was modelled as a uni-directional composite, the failure criteria developed for traditional laminates were adapted in this study. According to the models developed during the second World-Wide Failure exercise [25, 26], the theory developed by Pinho et al [27, 28] was one of the three better theories among all twelve proposed models and can be easily implemented into Abaqus. Therefore this theory was adapted in this work to predict the failure behaviour of each component of the 3D composites. In addition, the widely used Maximum Stress failure criterion was also used as a reference. The strength properties of the tows used for both failure criteria were calculated using the following equations [29].

$$
\begin{gathered}
X_{T}=X_{T f} V_{p f}+X_{T m}\left(1-V_{p f}\right) \\
Y_{T}=\frac{X_{T m}}{\frac{E_{m}}{E_{22}\left[\frac{2 r_{f}}{s_{f}}\left(\frac{E_{m}}{E_{2 f}}-1\right)+1\right]}} \\
S_{T}=\frac{S_{T m}}{\frac{G_{m}}{G_{23}\left[\frac{2 r_{f}}{s_{f}}\left(\frac{G_{m}}{G_{f 23}}-1\right)+1\right]}}
\end{gathered}
$$

The longitudinal and transverse compressive strength, and the in-plane shear strength do not have well-established accurate analytical solutions, and the compressive and shear properties of the fibres were not found in the literature. Therefore these properties of the tows were assumed to be the same as the laminates used in [30], which have similar fibre and matrix strength.

\subsubsection{Maximum stress failure criterion}

The maximum stress failure criterion states that once the stress of an element reaches the strength of the material it is considered to have failed. For the pure resin elements the principal stresses were used to calculate the failure index, and for the tow elements the stresses in the material direction were used to calculate the failure index. For the maximum stress failure criterion, the element was directly deleted after the failure index reached unity. The tensile failure of the warp tows were the dominant failure model rather than the transverse and shear failure, therefore only the Longitudinal Tensile Failure Index was used as a criterion for element deletion. All other failure indices were calculated in VUMAT but not used for element deletion. 


\subsubsection{Pinho's failure criterion}

\section{Failure initiation}

The failure criterion developed by Pinho et al [27, 28] defined independent failure indices for different types of failure modes and also defined the crack initiation state and propagation state. The pure polymer failure, matrix failure within the composites, and fibre tensile failure criterion were included in the model. The thick-embedded-ply matrix failure criterion developed in $[27,28]$ was used in the unit cell model since the thickness of the tow $(0.46 \mathrm{~mm})$ is higher than the thickness of a typical lamina $(0.125 \mathrm{~mm})$. All materials in this model were assumed to have linear elastic behaviour before failure initiates, therefore the criterion set for linear elastic fracture was used. The failure indices used to determine failure initiation are listed below.

Pure Polymer Failure Index $\left(F I_{p}\right)[27,28]$ :

$$
\begin{gathered}
F I_{p}=\frac{3\left(k^{2}-\left(X_{T m}-X_{C m}\right) \sigma_{h}\right)}{X_{T m} X_{C m}} \\
k=\sqrt{\frac{\left(\sigma_{P 1}-\sigma_{P 2}\right)^{2}+\left(\sigma_{P 2}-\sigma_{P 3}\right)^{2}+\left(\sigma_{P 3}-\sigma_{P 1}\right)^{2}}{6}} \\
\sigma_{h}=\frac{\sigma_{x}+\sigma_{y}+\sigma_{z}}{3}
\end{gathered}
$$

where $\sigma_{P 1}, \sigma_{P 2}$, and $\sigma_{P 3}$ are the maximum, middle, and minimum principal stress, $\sigma_{h}$ is the hydrostatic pressure, and $\sigma_{x}, \sigma_{y}$, and $\sigma_{z}$ are the stresses in the global coordinate system, $X_{T m}$ and $X_{C m}$ are the tensile and compressive strength of resin.

Fibre Tensile Failure Index $\left(F I_{f}\right)[27,28]$ :

$$
F I_{f}=\frac{\max \left(0, \sigma_{1}\right)}{X_{T}}
$$

Intra-tow Matrix Failure Index $\left(F I_{m}\right)[28]$ :

$$
F I_{m}=\left(\frac{\tau_{N M}}{S_{T}^{i s}-\eta_{T} \sigma_{N}}\right)^{2}+\left(\frac{\tau_{N L}}{S_{L}^{i s}-\eta_{L} \sigma_{N}}\right)^{2}+\left(\frac{\max \left(0, \sigma_{N}\right)}{Y_{T}^{i s}}\right)^{2}
$$

where $\tau_{N M}, \tau_{N L}$, and $\sigma_{N}$ are the traction components on the potential matrix fracture plane. $Y_{T}^{i s}, S_{L}^{i s}$, and $S_{T}^{i s}$ are the in-situ transverse tensile strength, in-situ longitudinal shear strength, and in-situ transverse shear strength, which were calculated using Equation 8 [28]. The friction coefficients $\eta_{T}$ and $\eta_{L}$ account for the effect of pressure on the fracture behaviour, and the values used by Pinho et al. [28] $\left(\eta_{T}=0.287, \eta_{L}=0.082\right)$ were used this paper.

$$
\begin{gathered}
Y_{T}^{i s}=1.12 \sqrt{2} Y_{T} \\
S_{L}^{i s}=\sqrt{2} S_{L} \\
S_{T}^{i s}=\sqrt{2} S_{T}
\end{gathered}
$$

Failure propagation

After failure initiation (failure indices reach unity), the corresponding failure mode develops into 
a propagation region. The failure progression is different for different failure modes, but all follow this common approach: the constitutive law is modified after failure initiation, which gradually reduces the traction components on the potential fracture plane to zero using a damage evolution factor $d$ as shown in Equation 9 [28].

$$
\boldsymbol{\sigma}_{l m n}=\left\{\sigma_{l}, \sigma_{m},\left(1-\frac{\max \left(0, \sigma_{n}\right)}{\sigma_{N}} d\right) \sigma_{n}, \tau_{l m},(1-d) \tau_{n m},(1-d) \tau_{n l}\right\}
$$

where $\boldsymbol{\sigma}_{l m n}$ is the degraded effective stress tensor acting on the fracture plane, the six stress components were obtained by stress transformation, and damage evolution factor $d$ was defined for two scenarios: $0^{\circ}$ fracture angle and non-zero fracture angle.

\section{Pure Polymer Failure}

For the pure resin failure, the damage evolution factor was set to unity immediately after failure initiation.

\section{Fibre Tensile Failure}

The fibre tensile failure was considered to be brittle and fatal, which occurred normal to the fibre direction. A triangle law was used to define the degradation: once the Fibre Failure Index $F I_{f}$ reached one, the element entered the degradation region. The degradation factor $\mathrm{d}$ was defined by Equation 10 and the failure strain $\varepsilon^{f}$ was defined in Equation 11 [28].

$$
\begin{gathered}
d^{\text {inst }}=\max \left\{0, \min \left\{1-\frac{\sigma^{0}}{\bar{\sigma}} \frac{\varepsilon^{f}-\varepsilon^{e l}}{\varepsilon^{f}-\varepsilon^{0}}, 1\right\}\right\} \\
d=\max _{\text {time }}\left\{d^{i n s t}\right\} \\
\varepsilon^{f}=2 \frac{G_{I c} / l}{\sigma^{0}}
\end{gathered}
$$

where $G_{I c}$ is the critical energy release rate for fibre tensile failure, and $l$ is the characteristic length of the element. The $G_{I c}$ value $\left(92 \mathrm{~kJ} / \mathrm{m}^{2}\right)$ in [28] was used in this paper as the materials are similar.

\section{Intra-tow Matrix Failure}

The matrix failure was categorised into two failure scenarios: zero degree cracking angle and non-zero degree cracking angle [28]. For zero degree matrix crack, the stresses can still be transmitted to the failed layer by the shear force on the adjacent layers after the first matrix crack has occurred. The cracks will keep accumulating until they reach a saturation state when the distance between two adjacent cracks is too small to transmit stresses. The crack saturation density $n$ was calculated using Equation 12. Once the damage saturated, the cracks propagated into delamination, and the damage evolution factor can be expressed with the mode II interlaminar critical energy release rate $G_{I I c}$ as shown in Equation 12. The highest damage factor $d$ throughout time was used to degrade the traction stresses. 


$$
\begin{gathered}
\varepsilon^{d}=\varepsilon^{0}+\frac{2 n G_{c}}{\sigma^{0}} \\
\varepsilon^{f}=\frac{2 G_{I I c}}{\sigma^{0} t} \\
n=\frac{S_{L}^{i s}}{h Y_{T}^{i s}} \\
d^{i n s t}=\max \left\{0, \min \left\{1-\frac{\sigma^{0}}{\bar{\sigma}}, 1-\frac{\sigma^{0}}{\bar{\sigma}} \frac{\varepsilon^{f}-\varepsilon^{e l}}{\varepsilon^{f}-\varepsilon^{d}}, 1\right\}\right\} \\
d=\max _{\text {time }}\left\{d^{\text {inst }}\right\}
\end{gathered}
$$

where $\varepsilon^{0}$ is the failure onset strain that obtained when the failure index reaches one, $\sigma^{0}$ is the magnitude of the traction at failure onset, $G_{c}$ is the critical energy release rate of the failure mode, $n$ is the saturation crack density, $\varepsilon^{f}$ is the strain at final failure, $G_{I I c}$ is the model II interlaminar critical energy release rate, $t$ is the thickness of the element, $S_{L}^{i s}$ is the in-situ longitudinal shear strength, $Y_{T}^{i s}$ is the in-situ transverse tensile strength, $\mathrm{h}$ is the thickness of the tow, $\bar{\sigma}$ is the magnitude of the instant traction, $\varepsilon^{e l}$ is the magnitude of the elastic strain vector on the fractured plane, $d^{\text {inst }}$ is the instantaneous damage evolution factor. The $G_{I I c}$ value $\left(0.8 \mathrm{~kJ} / \mathrm{m}^{2}\right)$ in $[28]$ was used in this paper as the materials are similar.

For a matrix crack with a non-zero fracture angle, a wedge effect will promote the delamination. A triangle law similar to fibre tensile failure propagation was used to define the degradation factor $\mathrm{d}$ with the failure strain expressed in Equation 13 [28]. More details of this failure criterion can be found in [28], and more detailed on the parameters can be found in [31].

$$
\varepsilon^{f}=2 \frac{G_{c} / l+G_{I c} / t}{\sigma^{0}}
$$

where $G_{c}$ is the critical energy release rate of the failure mode, $G_{I c}$ is the critical energy release rate for matrix tensile failure, and the $G_{I c}$ value $\left(0.21 \mathrm{~kJ} / \mathrm{m}^{2}\right)$ in [28] was used in this paper as the materials are similar.

\section{Results and discussion}

\subsection{Unit cell model}

The predicted tensile properties of both damage models are summarised in Table 6. As can be seen both models over estimated the tensile strength by less than $15 \%$ for both weaves. Moreover, Pinho's damage model predicted a higher strength than the Max-Stress model in both weaves. Since Pinho's damage criteria defined the damage propagation after failure initiated and the Max-Stress model deleted the element immediately after failure initiated, it stands to reason that Pinho's damage model predicted a higher strength. In both damage models, matrix failure occurred first around the binding points and the warp tow tensile failure occurred last which resulted in the final fracture.

Two models with the binder tows replaced by matrix elements were also created to investigate the effect of the binder tow. The results showed that replacing the binder tows did not affect the properties of W-1 but slightly reduced the strength of W-3. Since the binder fibre volume fraction in 
W-3 was higher than $\mathrm{W}-1$ and the angled binders contributed more to the longitudinal properties than the orthogonal binders, it stands to reason that replacing the angled binders with matrix caused a reduction in tensile strength. However, since the warp tow dominated the final fracture, the reduction in ultimate strength was very limited. Although the numerical model showed that the binder tows had little effect on the tensile performance of the 3D woven composites, the actual binder tows in reality influence the tensile properties by affecting the waviness of the warp tows, a feature that was not replicated in the model.

Figure 7 and Figure 8 show the stress-strain curves from both damage models of W- 1 and W-3 along with the upper and lower bounds of the experimental results. In both weaves, the two damage models produced similar stress-strain curves with the Max-Stress criteria producing slightly lower stresses. Both damage models deviated from the linear-elastic behaviour from about 0.005 strain due to matrix cracking and the deleted matrix elements. The modelled stress-strain curves of W-1 were closer to the upper bound of the experimental data and the results of W-3 model were closer to the lower bound.

\subsubsection{Maximum stress failure criterion}

Figure 9 shows the resin crack propagation of half of the W-1 model using the Max-Stress criteria plotted with the Longitudinal Tensile Failure $\left(F I_{X_{T}}\right)$ index. The resin cracks initiated at the outside of the binding points as highlighted in the red circles, and propagated along the binder tow in the thickness direction. The resin cracks also propagated along the width from the binding points to the boundary of the model as can be seen from Figure 9 b). All of the failed resin elements were caused by the maximum principal stress being higher than the resin tensile strength, and the Compressive Failure Index $F I_{X_{C}}$ of all resin elements never reached unity. The thin layer of resin between the surface weft tow and the outer warp tow started to fail and formed a debonding feature of the warp tow as shown in Figure 10. This debonding feature started from the binding points between the outer warp tows and weft tows, and later occurred around the inner warp tows. All of the thin layers of resin failed completely at $570.76 \mathrm{MPa}$ and were deleted from the model thereafter, which meant there were only a limited amount of matrix elements left to transfer load between warp tows and weft tows. Moreover, more resin elements failed and were deleted due to tensile failure with the increasing load, such as the elements in the resin pocket between the warp and binder tows.

The transverse tensile failure index $F I_{Y_{T}}$ first reached unity in the surface weft elements which were not interlaced by the binder tows as shown in Figure $11 \mathrm{a}$ ), and later at 411.04 MPa it reached unity in the inner weft tows when the matrix cracks propagated as shown in Figure $11 \mathrm{~b}$ ). At 411.04 MPa, the matrix cracks had already propagated through the thickness which disconnected the surface weft tows from loading, therefore the index $F I_{Y_{T}}$ decreased in these regions and increased in the inner weft tows where the load was still transferred by the matrix. As the deleted resin region propagated further, $F I_{Y_{T}}$ dropped below unity in all of the weft tows after $627.64 \mathrm{MPa}$ due to the loss of load transferring medium. The post-failure microscopic image in Figure $13 \mathrm{~b}$ ) showed that transverse matrix cracking (transverse tensile failure) existed in the surface weft tows but not in the inner weft tows. Since the inner weft tow transverse failure was predicted to initiate later than the surface weft tow transverse failure, this intact inner weft tow indicated that the failure process was predicted correctly but the failure initiation stress was under-predicted possibly due to the 
under-estimated transverse tensile strength of the tows.

Although the transverse tensile failure was predicted by the model at an early stage of loading, it did not affect the predicted strength since it was not used for element deletion and therefore not involved in the damage evolution process. The final failure was only caused by the longitudinal tensile failure of the warp tow and progressive matrix cracking.

The modelled failure process of $\mathrm{W}-3$ was similar to $\mathrm{W}-1$. The matrix cracking started first near the binding points and propagated in the width and thickness directions, and the warp tow tensile failure caused the final fracture of the unit cell.

\subsubsection{Pinho's failure criterion}

The Pinho's failure criterion predicted higher failure stress than the Maximum Stress criterion and also predicted different failure modes within the damage initiation and propagation stages. The first predicted damage initiation in W-1 was the intra-tow matrix cracking occurring in the binding points of the binder tow at $127.96 \mathrm{MPa}$. With the load increasing, the matrix failure index $\left(F I_{m}\right)$ of the elements in the surface weft tow regions also reached unity at $149.13 \mathrm{MPa}$ as shown in Figure 12. Although the predicted matrix cracking initiated at an early stage of loading, the intra-tow matrix failure stayed in the damage propagation region (the damage degradation factor did not reach unity) before final fracture, therefore no element was deleted due to intra-tow matrix failure.

According to the failure criteria, the intra-tow matrix cracks occurred at an angle $\alpha$ to the 1-2 plane in the local material coordinate system. This fracture angle was plotted at the last frame before final failure in Figure 13. As can be seen most of the inner weft tows and part of the surface weft tows exhibited a similar fracture angle of about $165^{\circ}$, and the cross-section of the failed sample showed matrix cracks with fracture angles of about $140^{\circ}, 150^{\circ}$, and $170^{\circ}$ in the surface weft tows but did not show any visible cracks in the inner weft tows. The model showed that the matrix failure initiated in the surface weft tows first at 240.26 MPa and then in the inner weft tows at 385.49 MPa. Therefore it stands to reason that the model under estimated the intra-tow matrix strength, possibly because the under-estimated transverse tensile strength of the tows, which was also suggested by the results of the Max-Stress model.

The failure behaviour of W-3 using Pinho's failure criterion was similar to using the Max-Stress Model. The first deleted elements were the resin elements in between the surface binder and the surface weft, which created a debonding feature. The resin cracks also initiated around the binding points at $323.47 \mathrm{MPa}$, and propagated along the binder in both width and thickness directions as shown in Figure 14. As the load increased, the debonding of the warp tow occurred and the tensile fracture of the warp tow resulted in the final failure.

Figure 15 shows the matrix cracking angle of the tows before final fracture. As can be seen the cracking angle distributions in the two weft tows at both sides of the binder tow were almost symmetrical, with the angle being smaller (around $50^{\circ}$ ) near the binder and being higher (around $160^{\circ}$ ) away from the binder. However, this phenomena was not observed in the experiments. The microscopic image of a failed W-3 sample showed that the matrix cracks in the surface weft tows were almost at $0^{\circ}$ (or $180^{\circ}$ ) to the thickness direction, and mostly occurred across the centre of the weft tow. No visible matrix cracks were observed in the warp and binder tow of the experimental samples. 


\subsection{Mosaic model}

\subsubsection{Un-notched model}

Table 7 shows the elastic modulus results obtained from the mosaic models. As can be seen, the modulus obtained from a coarse mesh model (nominal element size $0.85 \mathrm{~mm}$ ) and a fine mesh model (nominal element size $0.3 \mathrm{~mm}$ ) are almost identical. The predicted results from $\mathrm{W}-1$ mosaic models are slightly lower than the unit cell model and about $1.2 \%$ closer to the experimental value. The predicted modulus of W-3 mosaic model are also lower than the unit cell model and are less than 1\% higher from the experimental data possibly due to the angled binder orientation. Since the width of the sample is not dividable by the width of the unit cell, each mosaic model contains incomplete unit cells. Therefore it is reasonable that the results of the mosaic models differed from the unit cell models. Since there was less than $7 \%$ difference between the two modelling techniques and both models predicted modulus less than $15 \%$ higher than the experimental values, both models are considered to be valid for elastic modulus prediction.

The Max-Stress failure criterion used in the unit cell model was employed to define damage in the mosaic strength model. Table 7 lists the predicted tensile strength from both mosaic models along with the experimental results. All of the predicted strengths were about $10 \%$ higher than the experimental values and the mosaic model with finer mesh gave the lower predicted strength. In a model with coarser mesh, the stress of an element was averaged over a larger region than in a finer meshed model. Therefore the local stress level was lower in the coarser model than the finer model. Since the failure criterion was based on the stress level of the elements, the critical element in the finer mesh model reached its strength earlier and hence the model predicted lower ultimate tensile strength.

\subsubsection{Notched model}

The elastic mosaic models were applied to both standard sized (4.1 $\mathrm{mm}$ diameter) and enlarged (12.5 mm diameter) notched samples and only the fine-mesh models were used since the coarse mesh were not able to accommodate the notch. Figure 16-17 show the longitudinal strain distribution from the mosaic model and the experimental DIC results at similar load levels. As can be seen, the mosaic model predicted a similar strain distribution as the DIC, and the predicted distribution showed a more regular pattern due to the idealised model geometry. The longitudinal strain distributions along the centre line are also plotted as shown in Figure 16-17(c). Both models underestimated the strain levels possibly because the models used idealised geometry and material properties. The predicted strain distribution also showed similar trend to the DIC results. The lower strain regions are the binder tow areas which have higher stiffness than the surround matrix. The higher strain within the resin rich channels in W-1 (both standard and enlarged notch) was predicted by the mosaic model along with the higher strain concentration around the hole. This higher strain in the resin rich channels was caused by the lower local stiffness in these regions. Higher strain was also predicted at the centre of the weft flow region, and lower strain on the surface binder tow was also predicted. The DIC image also detected higher strain at the centre of the surface weft flow but did not show any clear lower strain in the binder tow. One possible explanation is that the binder tow in the actual sample had a curved path on the surface while the modelled binder tow had a straight 
path and was also longer in length. Therefore the modelled binder region would have a higher local stiffness than the actual sample, hence the predicted strain was lower.

The strain distribution predicted for both W-3 samples also showed similarity with the DIC results. The strain distribution around the notch was similar between the models and DIC images, especially the standard notch model. The higher strain in the resin channels was predicted by the mosaic model but was less pronounced from the DIC image. The real W-3 samples actually had smaller resin rich channels than the model since all of the actual tows were not rectangular shaped and were locally crimped. In addition, the model had a $0.18 \mathrm{~mm}$ thick resin layer covering most part of the surface while the actual sample only had a very thin layer of resin (less than $0.05 \mathrm{~mm}$ ) apart from at the binding points. These factors all accounted for the differences between the model and the DIC results.

Strength and damage analysis were also conducted on the notched W-1 and W-3 models using the same Max-Stress failure criterion and element deletion technique as the other strength models, and the predicted results are shown in Table 8 compared with the experimental results from [32]. The predicted open-hole tensile strength were significantly lower than the experimental results (at least $26 \%$ lower and up to $36 \%$ ). Clearly, the model needs further improvement before it can be used to predict the notched tensile strength.

The progressive damage modelled by element deletion showed that the pure matrix elements failed first in the resin channels near the notch and then the warp tows near the notch started to fail. However, the model reached its strength before the warp tow tensile failure started, which contradicts the experiments. This premature failure indicated that deleting the matrix elements is not suitable for this macro-scale model with stress concentration. In this macro model, each matrix element occupied a larger region (approximately $1 \times 10^{-2} \mathrm{~mm}^{3}$ ) than in the unit cell model (approximately $5 \times 10^{-4} \mathrm{~mm}^{3}$ ). A macro-scale gap was created by deleting a macro-level matrix element, which then resulted in the loss of load transfer between the tow elements and further caused the premature failure. Since the matrix elements in the unit cell model were smaller, deleting these elements can be treated as creating micro-level cracks which were observed from the experiments. Therefore it is valid to use element deletion in the unit cell model but not valid for the larger scale mosaic model.

The elastic modulus of an un-notched sample using this modified geometry were found to be similar to the original mosaic model and the experimental results as shown in Table 9. Therefore this modified geometry was considered to be valid. A modified model was created with the surface resin elements replaced by weft tow elements and the thickness of the tows changed as shown in Figure 18. As can be seen, the pure resin region in the modified model has been largely reduced, and the surface weft tows now have a varied cross-section that expands in the binder-free region. In the actual weave, the surface weft tows also have smaller cross-section area under the binder tows and the resin channels are clearly observed between the surface weft tows. Therefore the modified mosaic model represents the actual weave architecture better than the original model. A modified failure criterion was adapted from the Maximum Stress and Pinho's failure criterion to accommodate the problems with matrix cracking and progressive damage. Bogdanovich [33] proposed a damage progressive modelling scheme that degraded the stiffness of the damaged elements by a factor of $\alpha$ which related to the volume of failed elements and the volume of the intact elements. A simplified stiffness 
degradation scheme which used a constant degradation factor of 0.5 was used in the modified mosaic model. Since no experimental data was available for the matrix damage progression after failure initiation, this non-physically based arbitrary stiffness degradation scheme was used due to its simplicity.

As can be seen from Table 9, the modified mosaic models showed more than $9 \%$ improvement from the original models and only less than $20 \%$ difference existed between the modified models and the experimental results. Although the difference was still higher than the other modelling results, the shown improvement indicated that the mosaic technique can be used for macro-level simulation with an appropriate damage modelling scheme. Moreover, in the previous literature, an un-notched mosaic model proposed by Bogdanovich [33] using stiffness degradation scheme predicted a tensile strength $19 \%$ lower than the experiment data, and a $25 \%$ difference between model and testing results was considered as a success [11]. Therefore, this mosaic modelling technique was considered to be valid.

The failure process predicted by the mosaic models were similar between both weaves and both notches. The matrix failure within the resin rich channel near the notch started first and then the other matrix channels started to fail as shown in Figure 19. The failure of the surface matrix cracks were also observed in the resin rich channels in the failed samples. The warp tow tensile failure initiated around the notch at higher stress and propagated along the width as shown in Figure 20. The sample reached its tensile strength before the tensile crack reached the edge of the sample as can be seen from Figure $20 \mathrm{c}$ ) and d). The modelled warp tensile crack always propagated across an entire cross-section of a tow, which was also observed in the experiments.

\section{Conclusions}

A meso-scale unit cell model and a marco-scale mosaic model were developed to simulate the elastic and damage behaviour of W-1 and W-3 under tensile loading. Two failure criteria, the Maximum Stress and Pinho' criterion, were used along with element deletion to simulate the damage behaviour.

The unit cell model used an idealised geometry and predicted the tensile modulus and strength to about $10 \%$ higher than the experimental values. Several failure modes were predicted: matrix cracking, tow debonding, tow transverse tensile failure, and tow longitudinal tensile failure. The weft tow transverse failure was predicted first, followed by matrix cracking, weft and warp tow debonding, and finally warp tow tensile fracture.

The predicted elastic modulus and tensile strength of the un-notched mosaic model were about $10 \%$ higher than the experimental values, which were similar to the unit cell model. The mosaic model also simulated the tensile behaviour of an open-hole plate and predicted a similar strain distribution as the DIC experimental results. However, the predicted notch strength was about 10-21\% lower than the experimental data, possibly because the failure criterion and the macro-scale element did not capture the progressive fibre damage very well around the notch.

Overall, both models provided relatively accurate estimation of the tensile properties of 3D woven composites at different scale levels. Both failure criteria can be used to obtain strength properties 
with different failure modes. The mosaic model has the potential to simulate the behaviour of larger $3 \mathrm{D}$ woven structures if the notch behaviour and progressive fibre damage are implemented.

\section{Acknowledgements}

This research project is supported by the Aeronautical and Automotive Engineering Department of Loughborough University and M.Wright \& Sons Ltd. The help and support of the department staff and M.Wright \& Sons Ltd are gratefully acknowledged.

\section{Nomenclature}

$d \quad$ Damage evolution factor.

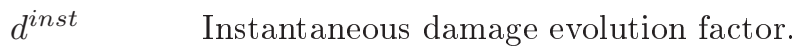

$E_{i} \quad$ Young's modulus in the i direction.

$F_{i} \quad$ Force applied in i direction.

FI Failure index.

$G_{c} \quad$ Critical energy release rate of the failure mode.

$G_{I I c} \quad$ Model II interlaminar critical energy release rate.

$G_{i j} \quad$ Shear modulus in i-j plane.

$S_{L} \quad$ Longitudinal shear strength.

$S_{T} \quad$ Transverse shear strength.

$V_{p f} \quad$ Packing factor, fibre volume fraction within a tow.

$V_{f} \quad$ Fibre volume fraction.

$X_{C} \quad$ Compressive strength of the composite in longitudinal direction.

$X_{T} \quad$ Tensile strength of the composite in longitudinal direction.

$Y_{C} \quad$ Compressive strength of the composite in longitudinal direction.

$Y_{T} \quad$ Tensile strength of the composite in transverse direction.

\section{Greek letters}

$\alpha \quad$ Inter-tow matrix fracture angle.

$\gamma_{i j}$ Shear strain in i-j plane.

$\varepsilon_{i}$ Direct strain in i direction.

$\nu_{i j}$ Poisson's ratio.

$\sigma_{i} \quad$ Direct stress in the i direction.

$\sigma_{n} \quad$ Traction component.

$\tau_{i j} \quad$ Shear stress in $\mathrm{i}-\mathrm{j}$ plane.

$\tau_{l m n} \quad$ Traction component in the l-m-n coordinate system.

\section{Superscripts}

$0 \quad$ Failure onset (strain, stress).

el Elastic (strain).

$f \quad$ Failure (strain, stress). 
In-situ property.

\section{Subscripts}

1, 2, $3 \quad$ Local coordinate system.

$f \quad$ Fibre.

$m \quad$ Matrix.

$p \quad$ Pure polymer (failure index).

$P i \quad$ Principal stresses.

$x, y, z \quad$ Global coordinate system.

\section{References}

[1] S. Li, Boundary conditions for unit cells from periodic microstructures and their implications, Composites Science and Technology 68 (9) (2008) 1962-1974.

[2] P. Tan, L. Tong, G. P. Steven, Behavior of 3D orthogonal woven CFRP composites. Part II. FEA and analytical modeling approaches, Composites Part A: Applied Science and Manufacturing 31 (3) (2000) 273-281.

[3] A. Drach, B. Drach, I. Tsukrov, Processing of fiber architecture data for finite element modeling of 3D woven composites, Advances in Engineering Software 72 (0) (2014) 18-27.

[4] S. D. Green, M. Y. Matveev, A. C. Long, D. Ivanov, S. R. Hallett, Mechanical modelling of 3d woven composites considering realistic unit cell geometry, Composite Structures 118 (0) (2014) 284-293.

[5] S. Buchanan, A. Grigorash, J. P. Quinn, A. T. McIlhagger, C. Young, Modelling the geometry of the repeat unit cell of three-dimensional weave architectures, Journal of the Textile Institute 101 (7) (2010) 679-685.

[6] Z. J. Wu, D. Brown, J. M. Davies, An analytical modelling technique for predicting the stiffness of 3D orthotropic laminated fabric composites, Composite Structures 56 (4) (2002) 407-412.

[7] W. S. Kuo, B. J. Pon, Elastic moduli and damage evolution of three-axis woven fabric composites, Journal of Materials Science 32 (20) (1997) 5445-5455.

[8] B. J. Thuruthimattam, N. K. Naik, Mechanical characterization of hybridized 3D orthogonally woven composites, Vol. 2 of Proceedings of the 39th AIAA/ASME/ASCE/AHS/ASC Structures, Structural Dynamics, and Materials Conference and Exhibition, Indian Inst of Technology, Mumbai, India, AIAA, Long Beach, CA, USA, 1998, pp. 953-961.

[9] S. C. Quek, A. Waas, K. W. Shahwan, V. Agaram, Compressive response and failure of braided textile composites: Part2-computations, International Journal of Non-Linear Mechanics 39 (4) (2004) 649-663. 
[10] S. Song, A. M. Waas, K. W. Shahwan, X. Xiao, O. Faruque, Braided textile composites under compressive loads: Modeling the response, strength and degradation, Composites Science and Technology 67 (15-16) (2007) 3059-3070.

[11] A. E. Bogdanovich, Progressive failure modeling and strength predictions of 3D woven composites, in: 50th AIAA/ASME/ASCE/AHS/ASC Structures, Structural Dynamics, and Materials Conference, American Institute of Aeronautics and Astronautics, Palm Springs, California, USA, 2009.

[12] S. J. Kim, C. S. Lee, H. Shin, L. Tong, Virtual experimental characterization of 3D orthogonal woven composite materials, in: Collection of Technical Papers - AIAA/ASME/ASCE/AHS/ASC Structures, Structural Dynamics and Materials Conference, Vol. 4, 2001, pp. 2912-2920.

[13] C. S. Lee, S. W. Chung, H. Shin, S. J. O. Kim, Virtual material characterization of 3D orthogonal woven composite materials by large-scale computing, Journal of Composite Materials 39 (10) (2005) 851-863.

[14] A. E. Bogdanovich, Three-dimensional analysis of anisotropic spatially reinforced structures, Composites Manufacturing 4 (4) (1993) 173-186.

[15] Q. Yang, B. Cox, Spatially averaged local strains in textile composites via the binary model formulation, Journal of Engineering Materials and Technology 125 (4) (2003) 418-425.

[16] B. N. Cox, W. C. Carter, N. A. Fleck, A binary model of textile composites: I. formulation, Acta Metallurgica et Materialia 42 (10) (1994) 3463-3479.

[17] J. Xu, B. N. Cox, M. A. McGlockton, W. C. Carter, A binary model of textile composites: II. the elastic regime, Acta Metallurgica et Materialia 43 (9) (1995) 3511-3524.

[18] P. Römelt, P. R. Cunningham, A multi-scale finite element approach for modelling damage progression in woven composite structures, Composite Structures 94 (3) (2012) 977-986.

[19] S. Dai, P. R. Cunningham, S. Marshall, C. Silva, Influence of fibre architecture on the tensile, compressive and flexural behaviour of 3d woven composites, Composites Part A: Applied Science and Manufacturing 69 (0) (2015) 195-207.

[20] S. V. Lomov, D. S. Ivanov, I. Verpoest, M. Zako, T. Kurashiki, H. Nakai, S. Hirosawa, Meso-FE modelling of textile composites: Road map, data flow and algorithms, Composites Science and Technology 67 (9) (2007) 1870-1891.

[21] C. C. Chamis, Simplified composite micromechanics equations for hygral thermal and mechanical properties, in: 38th Annual Conference Preprint - Reinforced Plastics/Composites Institute, Society of the Plastics Industry, NASA, Houston, TX, USA, 1983, pp. sess 21c-sess 21cp.

[22] J. Palaniappan, S. W. Boyd, R. A. Shenoi, J. Mawella, Repair efficiency of resin infused scarf repair to marine sandwich structures, in: 17th International conference on composite materials (ICCM 17), 2009. 
[23] J. C. H. Yee, S. Pellegrino, Folding of woven composite structures, Composites Part A: Applied Science and Manufacturing 36 (2) (2005) 273-278.

[24] J. Summerscales, Composites design and manufacture (2014).

[25] A. S. Kaddour, M. J. Hinton, Maturity of 3D failure criteria for fibre-reinforced composites: Comparison between theories and experiments: Part B of WWFE-II, Journal of Composite Materials 47 (6-7) (2013) 925-966.

[26] M. J. Hinton, A. S. Kaddour, The background to Part B of the second world-wide failure exercise: Evaluation of theories for predicting failure in polymer composite laminates under three-dimensional states of stress, Journal of Composite Materials 47 (6-7) (2013) 643-652.

[27] S. T. Pinho, G. M. Vyas, P. Robinson, Material and structural response of polymer-matrix fibre-reinforced composites: Part B, Journal of Composite Materials 47 (6-7) (2013) 679-696.

[28] S. T. Pinho, R. Darvizeh, P. Robinson, C. Schuecker, P. P. Camanho, Material and structural response of polymer-matrix fibre-reinforced composites, Journal of Composite Materials 46 (19-20) (2012) 2313-2341.

[29] J. A. Kies, N. R. L. W. D.C., Maximum Strains in the Resin of Fiberglass Composites, Defense Technical Information Center, 1962.

[30] A. S. Kaddour, M. J. Hinton, Input data for test cases used in benchmarking triaxial failure theories of composites, Journal of Composite Materials 46 (19-20) (2012) 2295-2312.

[31] S.Dai, Mechanical characterisation and numerical modelling of 3D woven composites. Loughborough University, UK, PhD Thesis (2014).

[32] S. Dai, P. R. Cunningham, S. Marshall, C. Silva, Open hole quasi-static and fatigue characterisation of 3d woven composites, Composite Structures 131 (2015) 765-774.

[33] A. E. Bogdanovich, Multi-scale modeling, stress and failure analyses of 3D woven composites, Journal of Materials Science 41 (20) (2006) 6547-6590. 


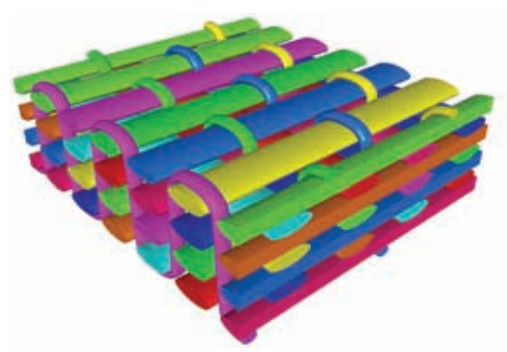

(a) W-1

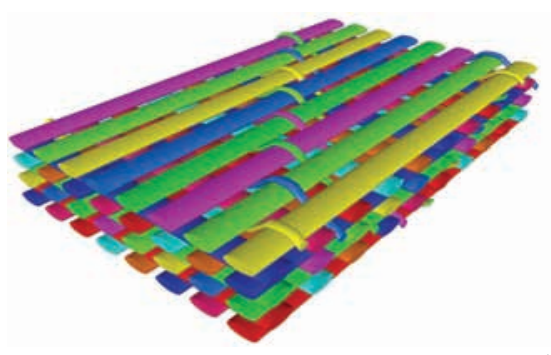

(b) W-3

Figure 1: Idealised weave architectures generated using TexGen.

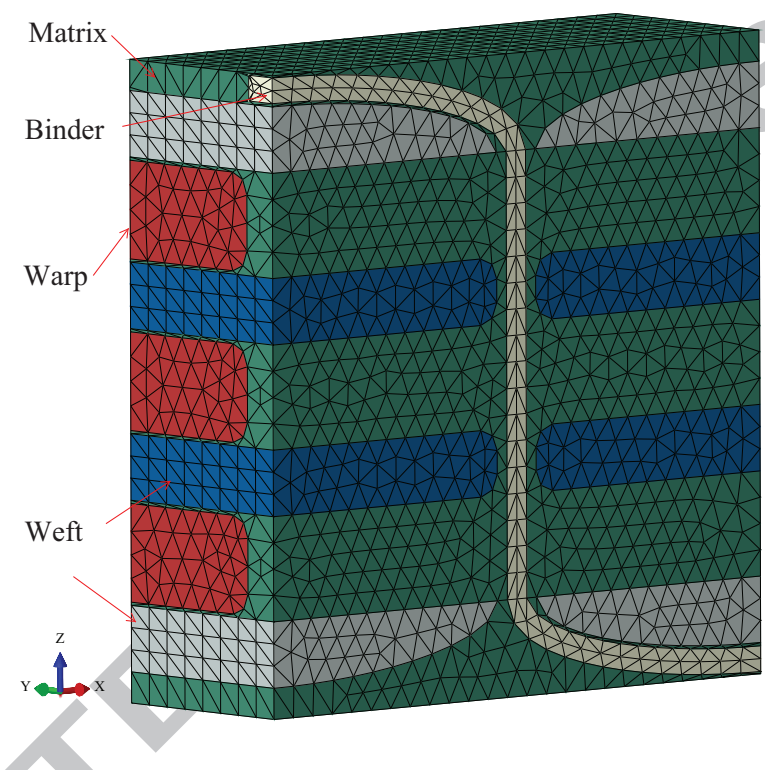

Figure 2: Quarter of the unit cell of W-1. 


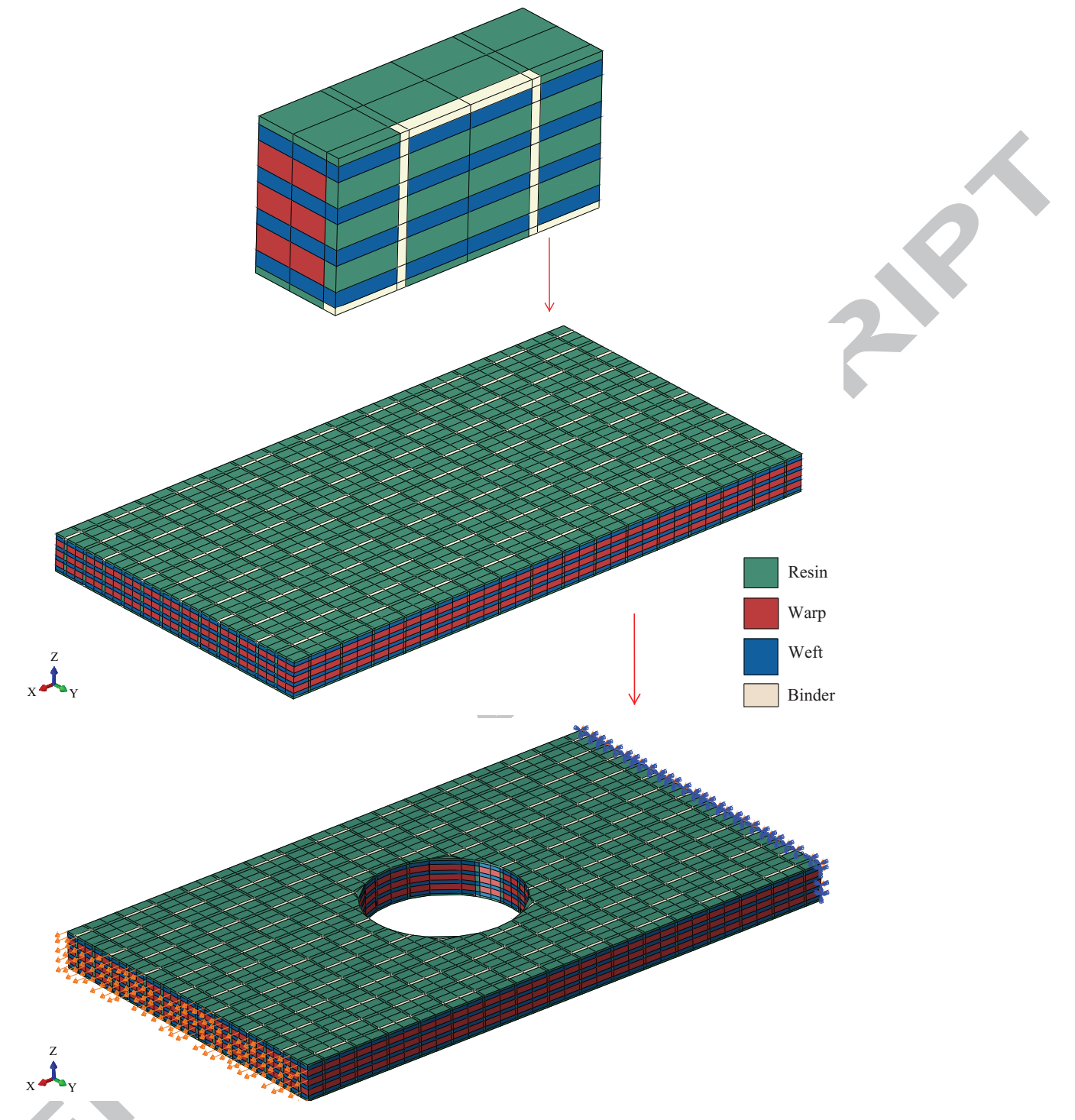

Figure 3: Mosaic model of W-1. 


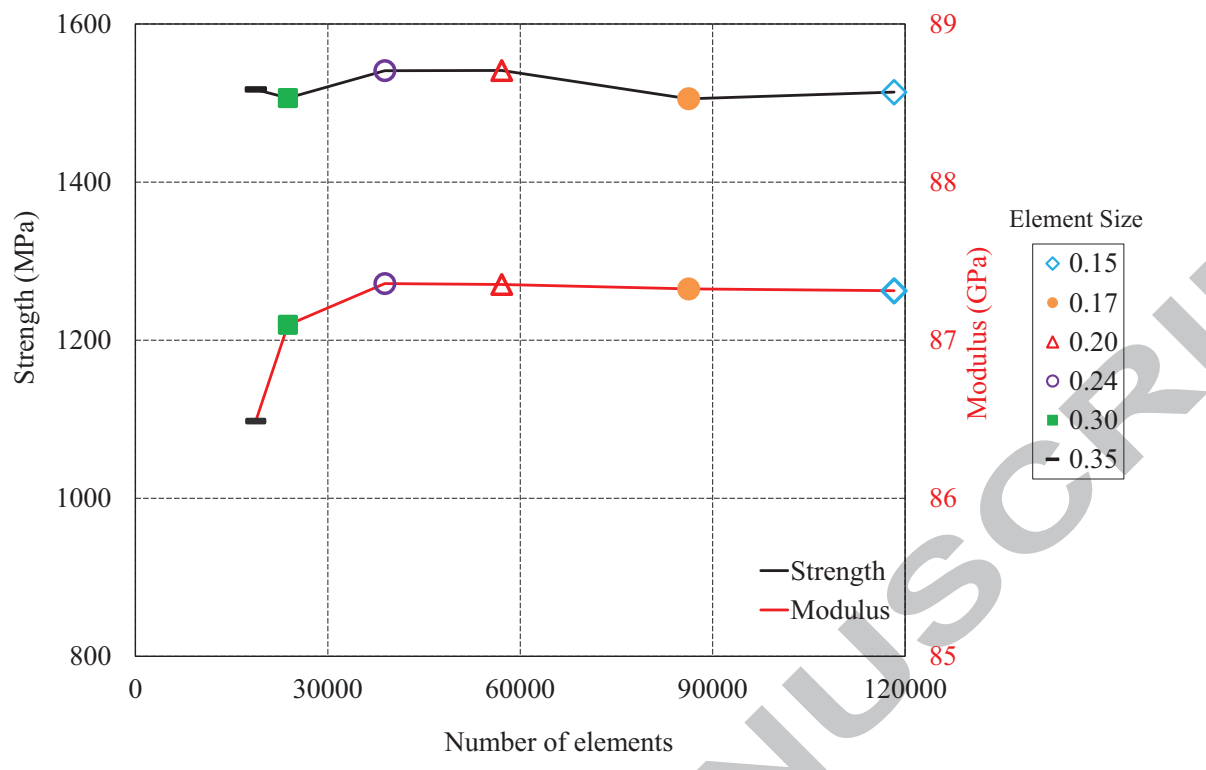

Figure 4: Elastic modulus $\left(E_{1}\right)$ and tensile strength of the models with different number of elements.

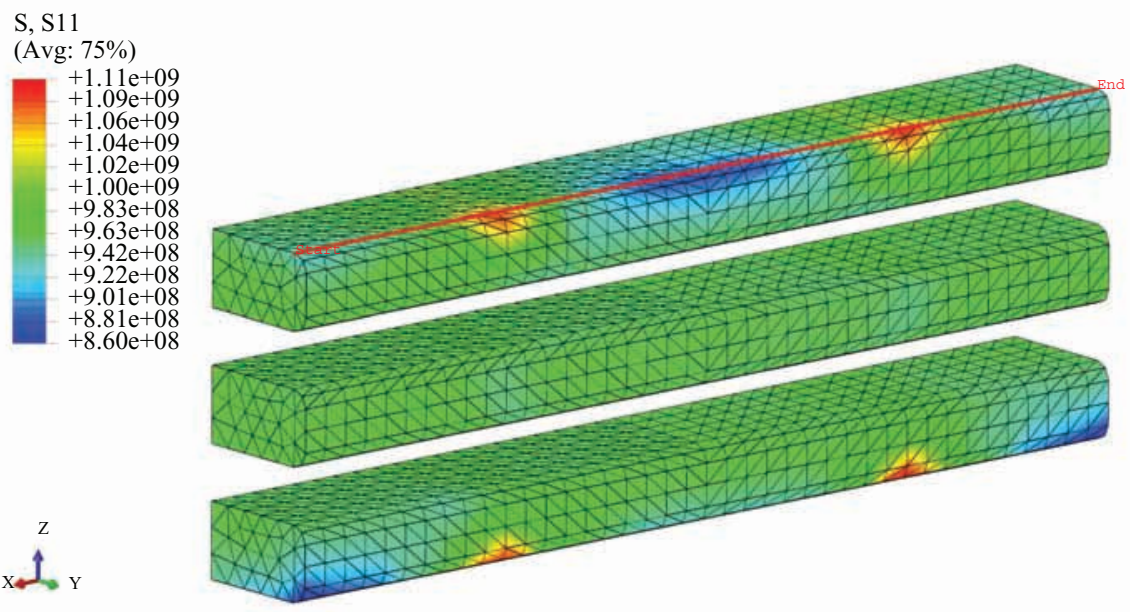

Figure 5: Longitudinal stress distribution on the warp tows at 4400 micro-strain in W-1 model with 0.15 mm mesh.. 


\section{ACCEPTED MANUSCRIPT}

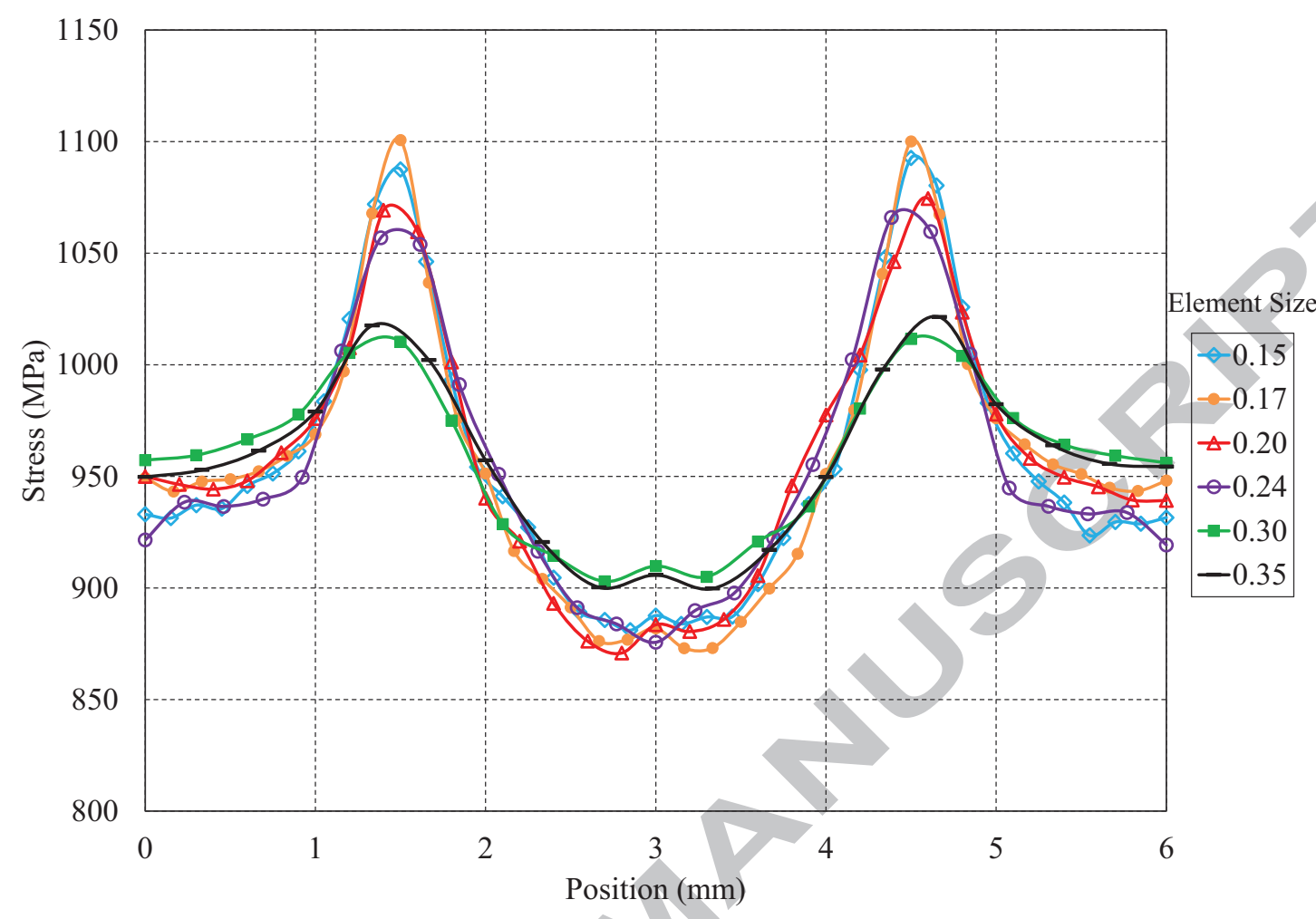

Figure 6: Longitudinal stress distribution on a warp tow of the Max-Stress models with different number of elements at 4400 micro-strain (failure initiation). 


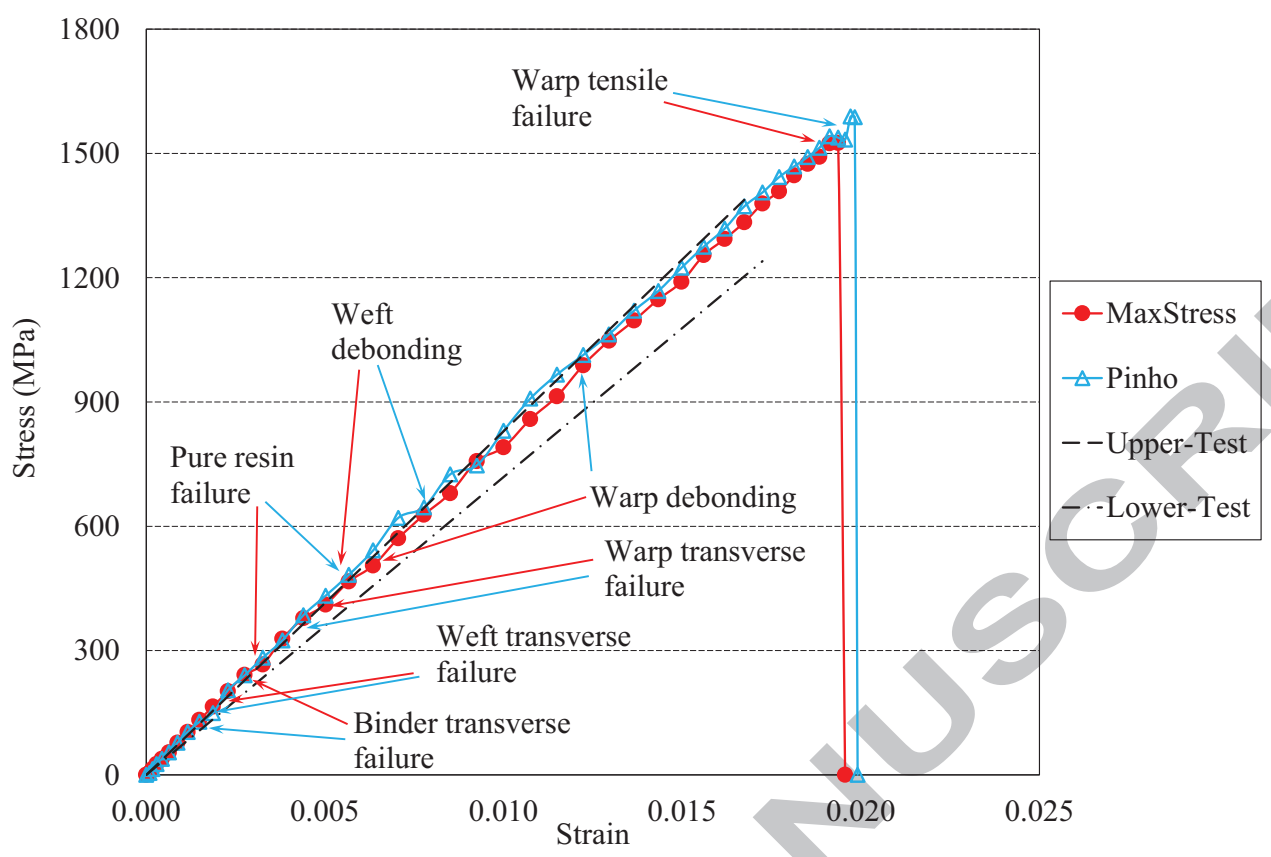

Figure 7: Stress-strain curves of W-1 models.

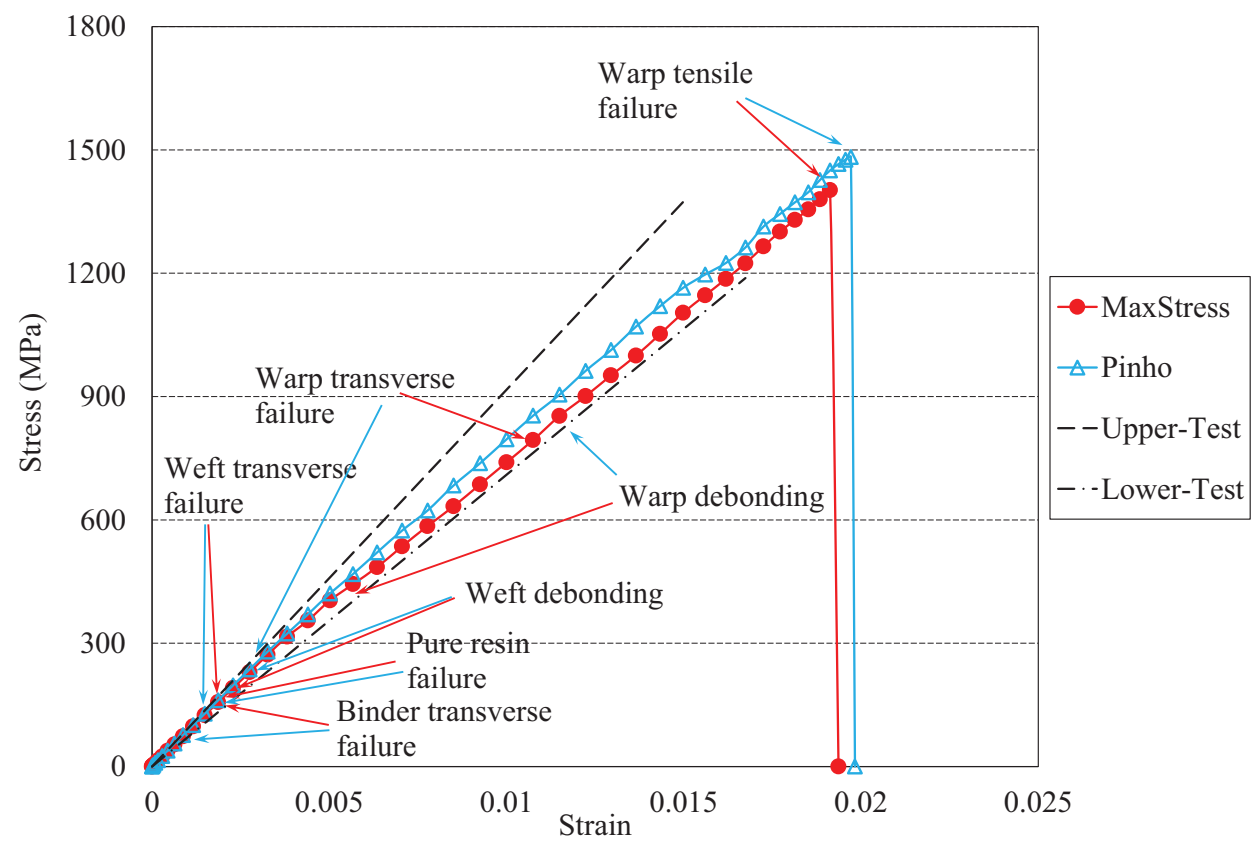

Figure 8: Stress-strain curves of W-3 models. 


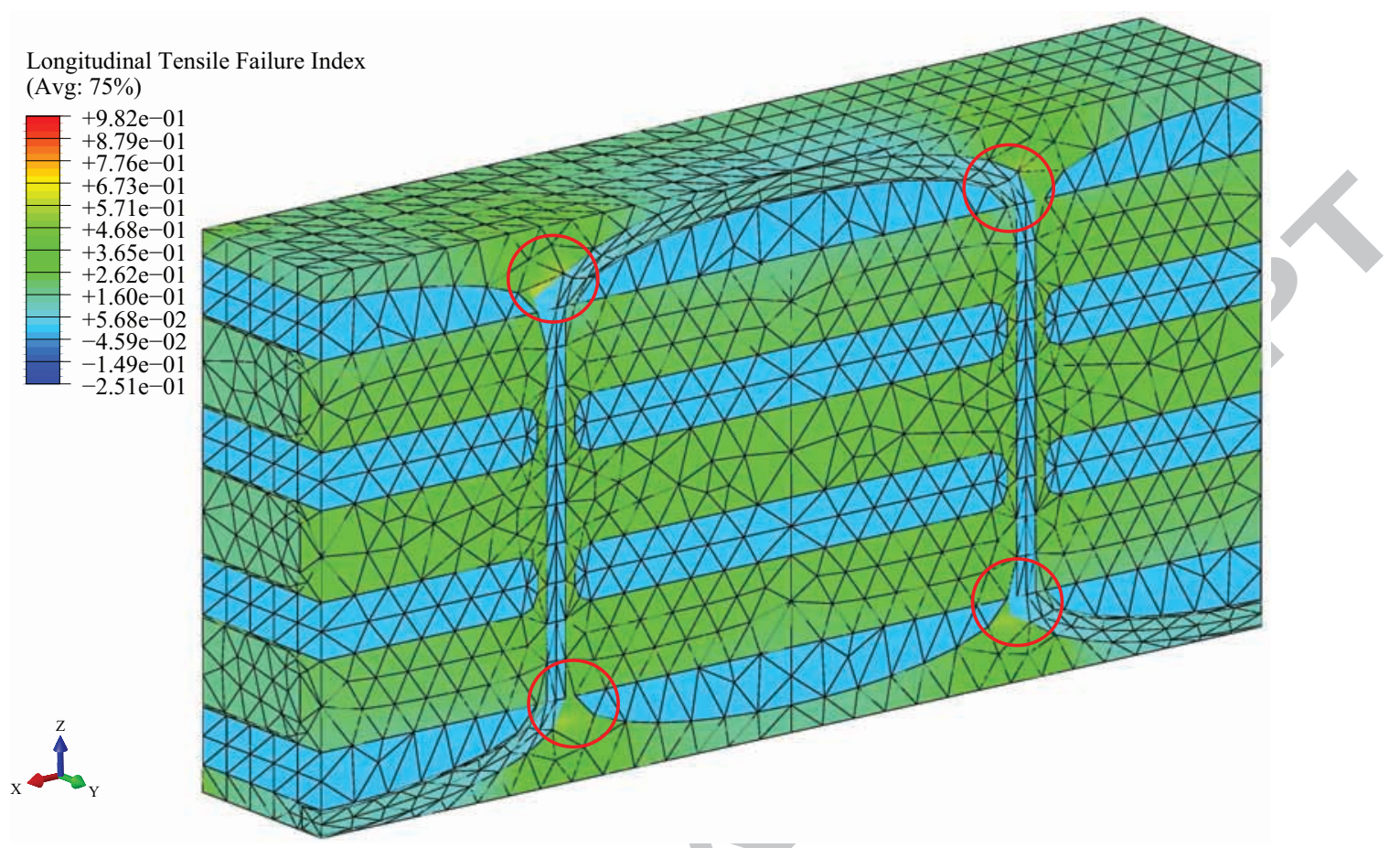

(a) at $266.53 \mathrm{MPa}$

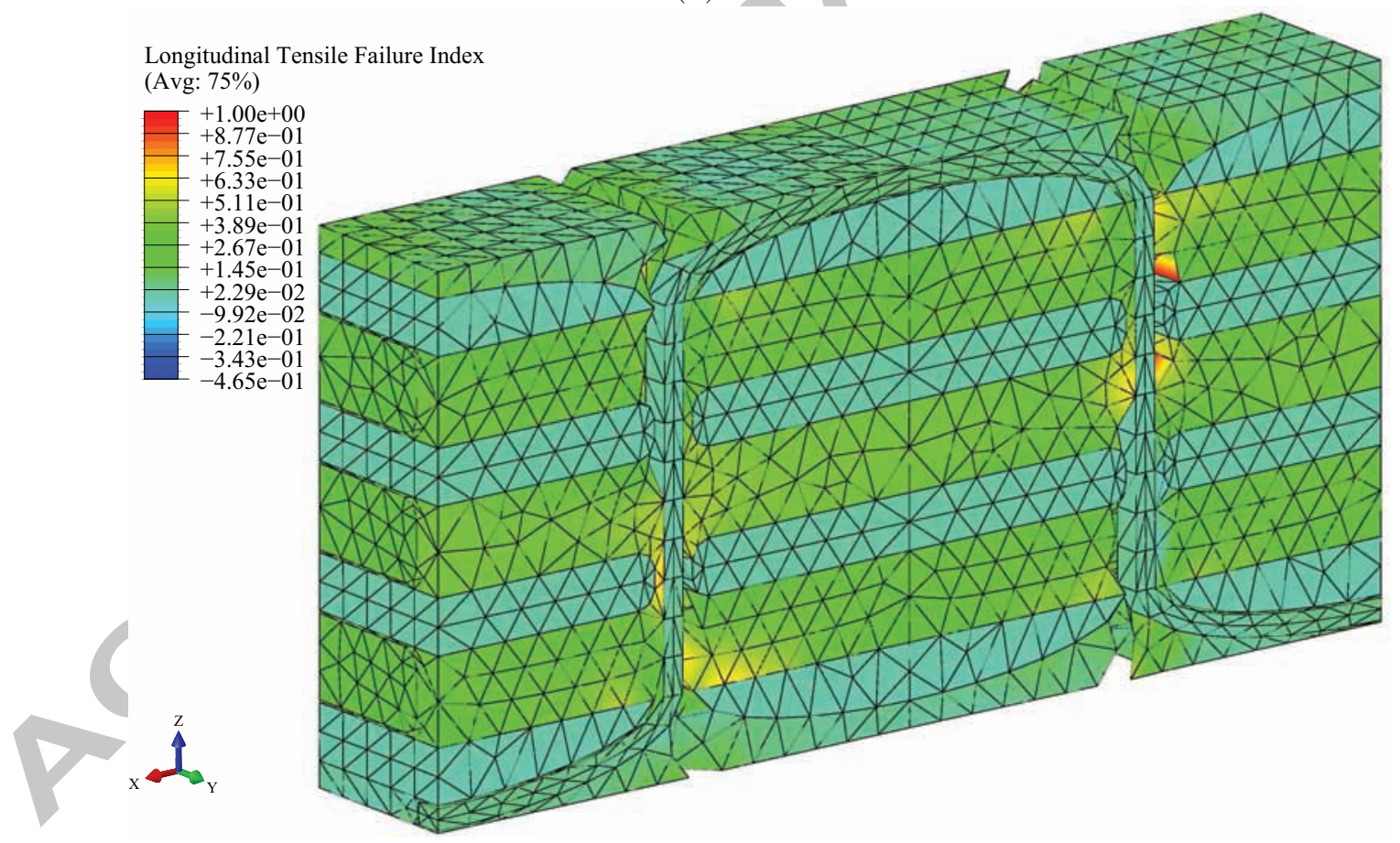

(b) at $411.04 \mathrm{MPa}$

Figure 9: Longitudinal tensile failure index $F I_{X_{T}}$ and matrix cracking propagation in the W-1-MaxStress Model. 


\section{ACCEPTED MANUSCRIPT}

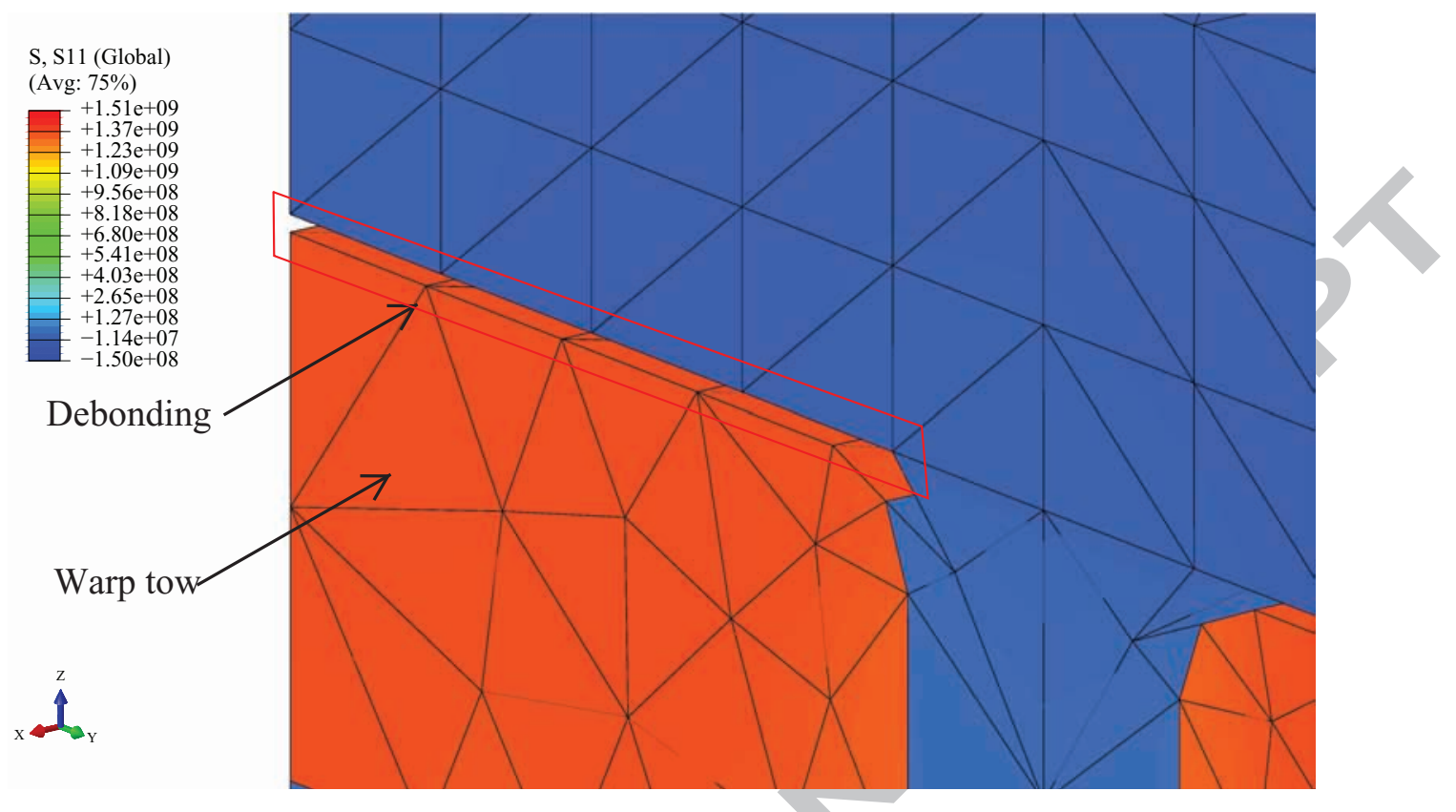

Figure 10: Tow debonding at 505.10 MPa in the W-1-MaxStress Model. 


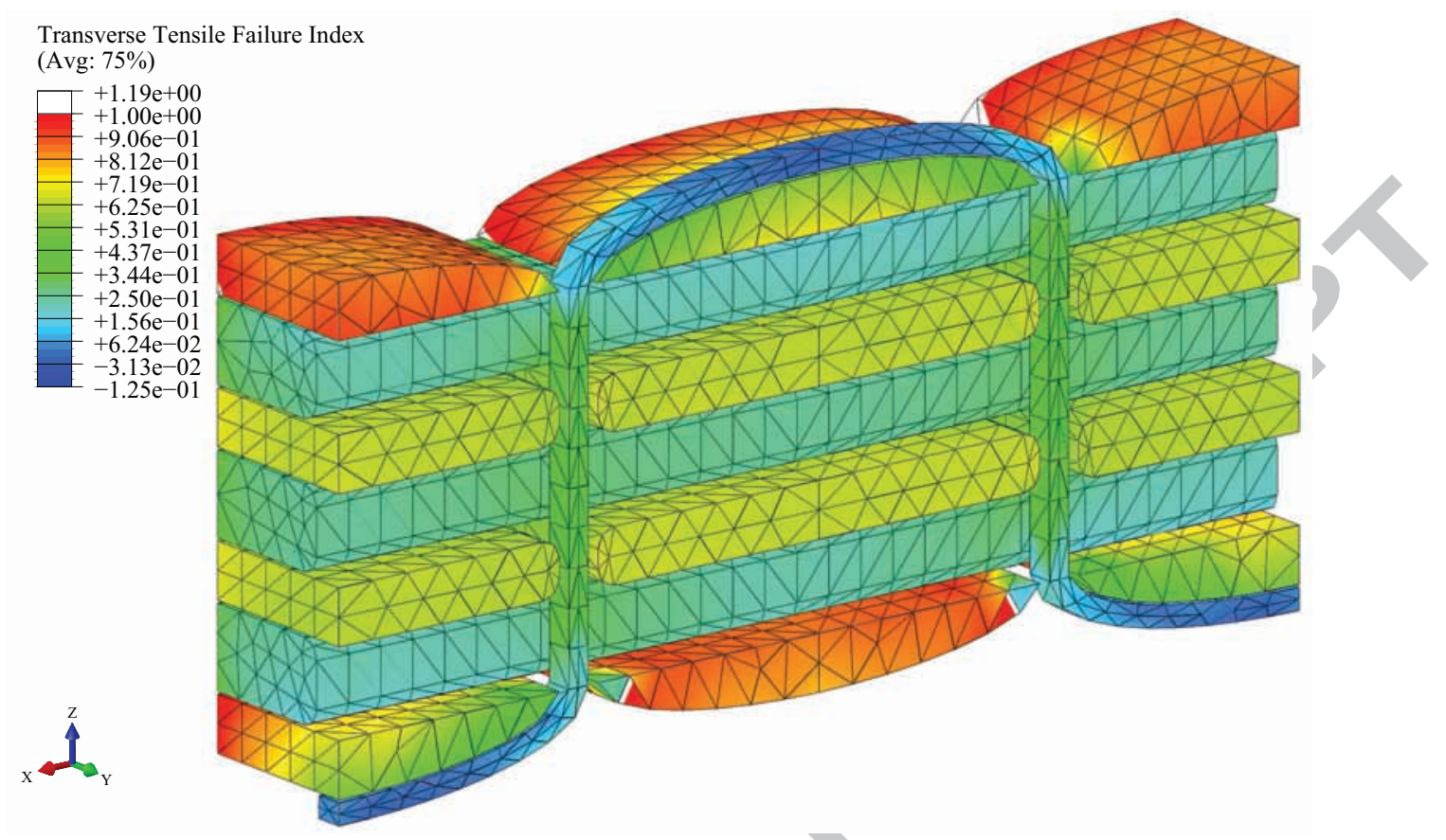

(a) at 266.53 MPa

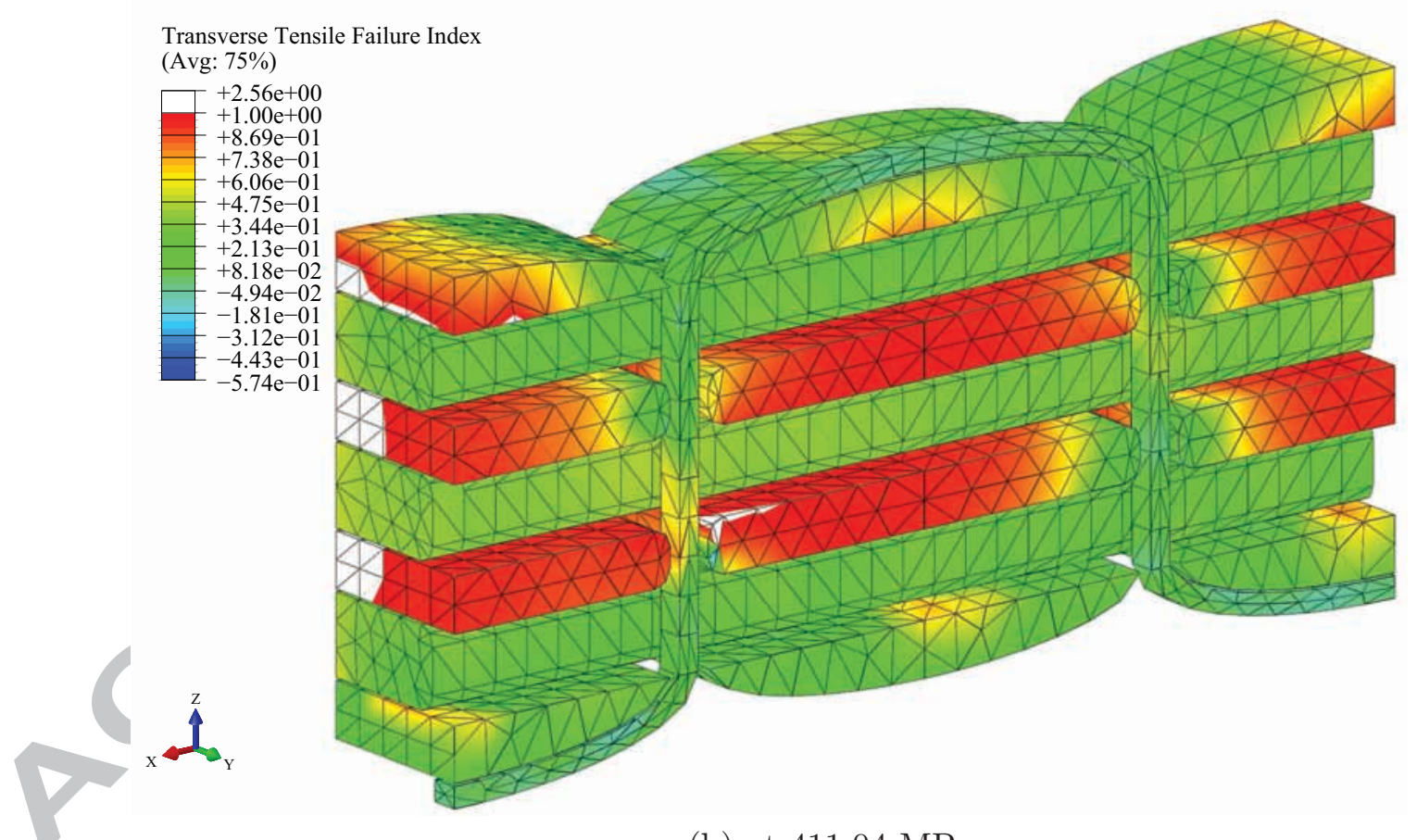

(b) at $411.04 \mathrm{MPa}$

Figure 11: Transverse tensile failure index $F I_{Y_{T}}$ of the tows at different stress levels in the W-1-MaxStress Model. 


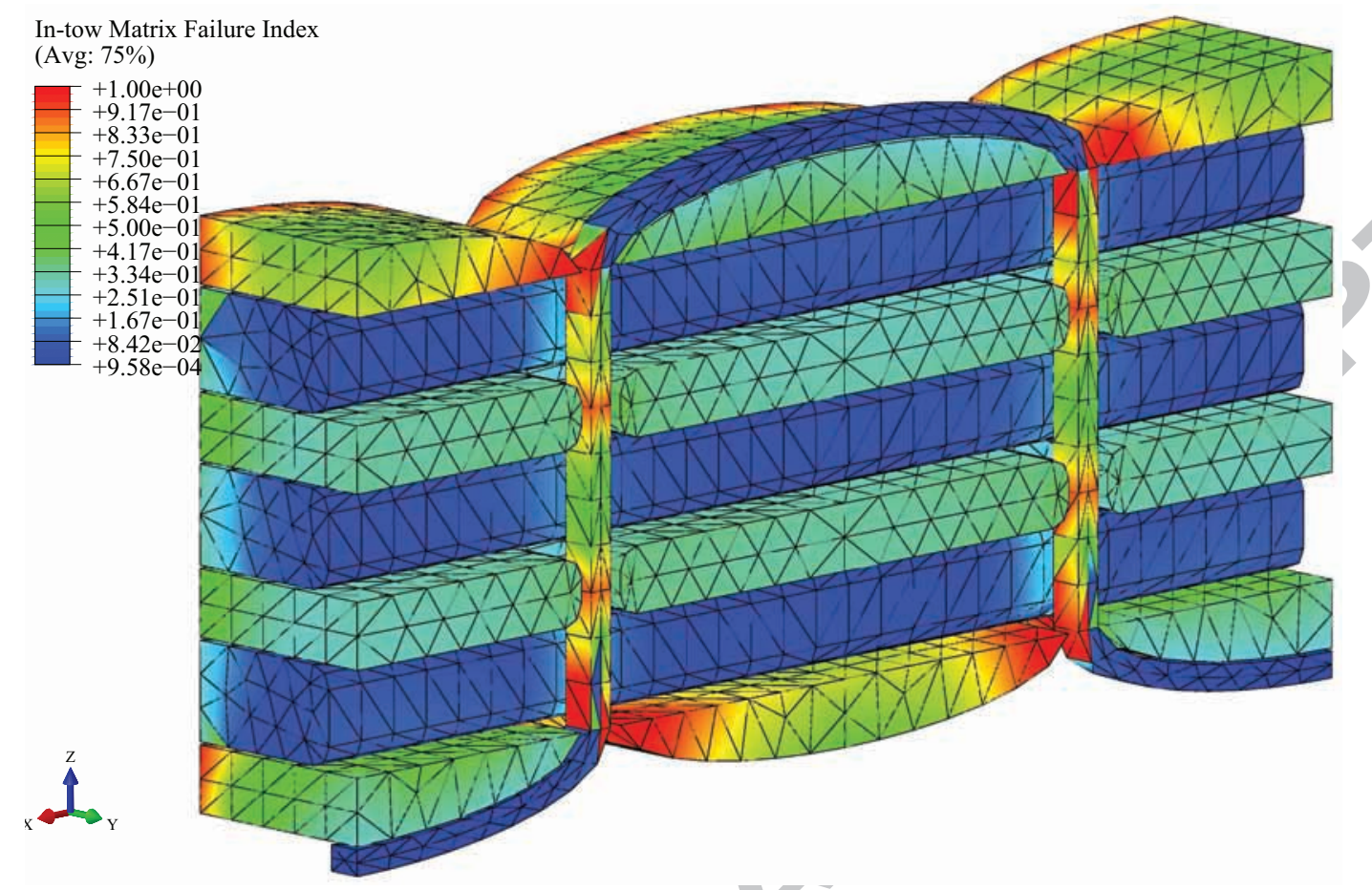

Figure 12: Intra-tow matrix failure index $F I_{m}$ at $149.13 \mathrm{MPa}$ in the W-1-Pinho Model. 


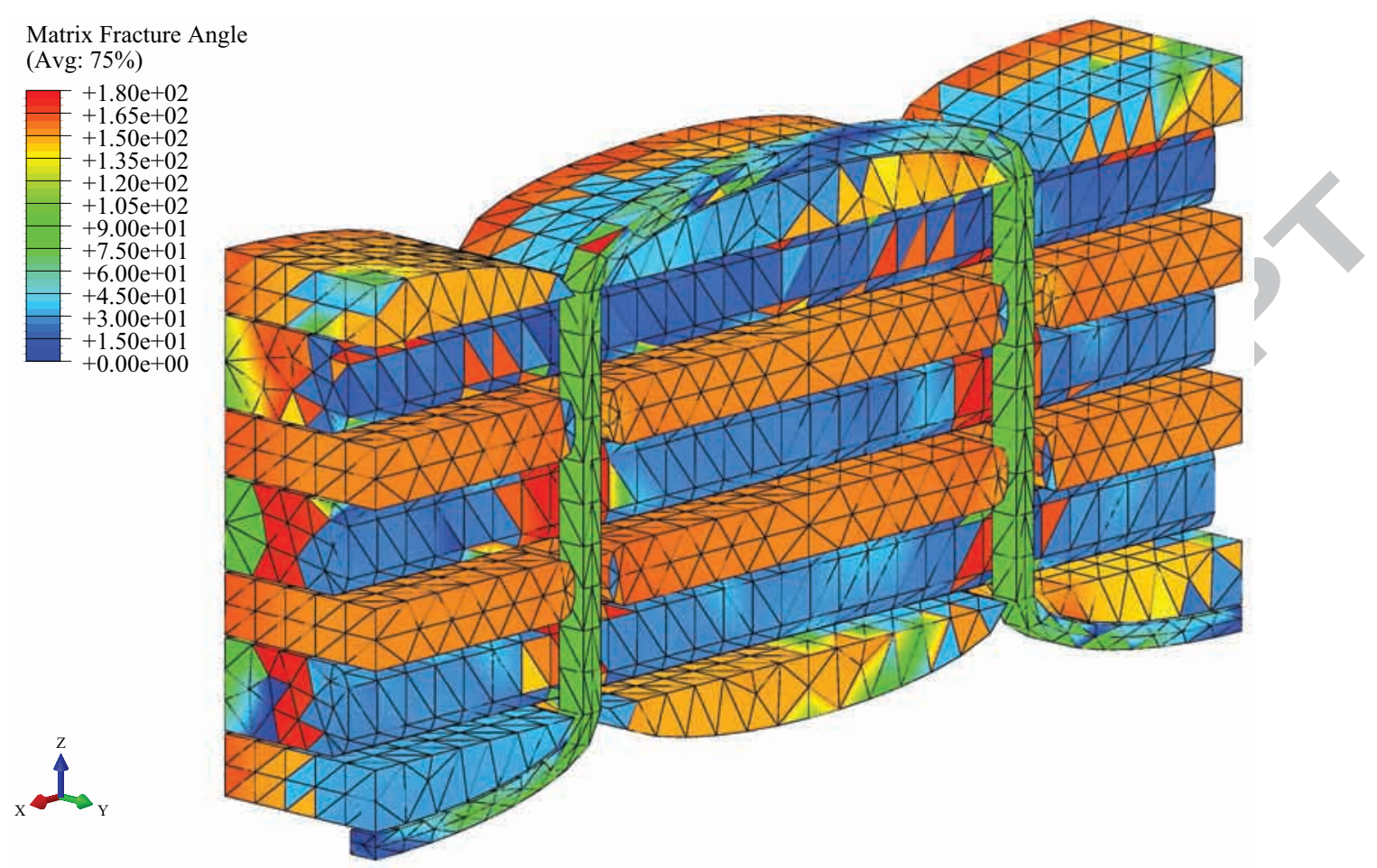

(a)

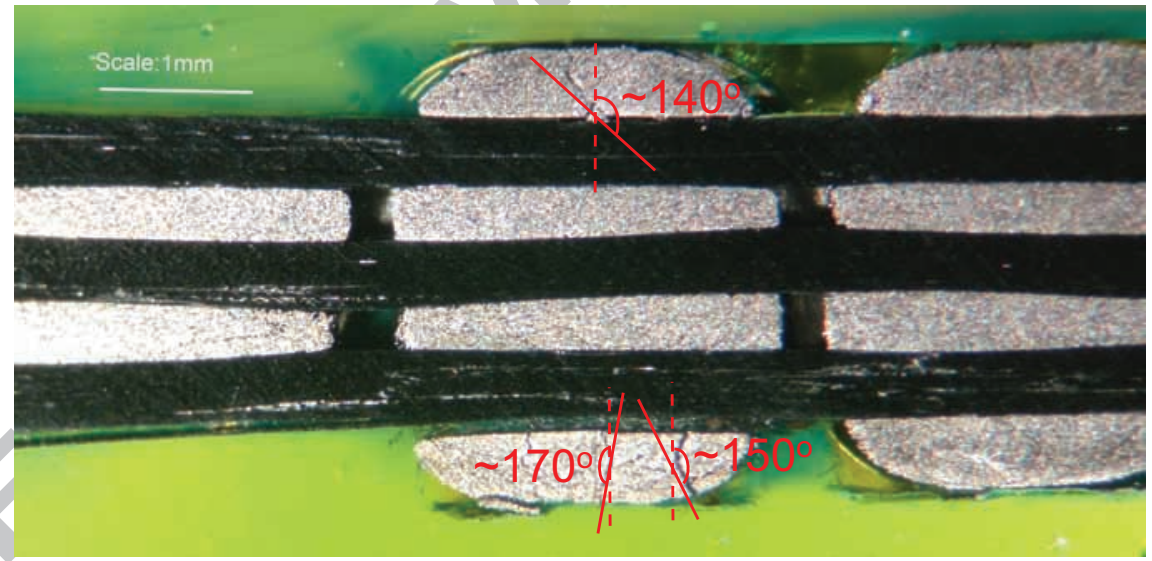

(b)

Figure 13: Intra-tow matrix fracture angle: (a) Distribution of the intra-tow matrix fracture angle $\alpha$ at $1587.36 \mathrm{MPa}$ in the W-1-Pinho Model, (b) Failed section showing fracture angle. 


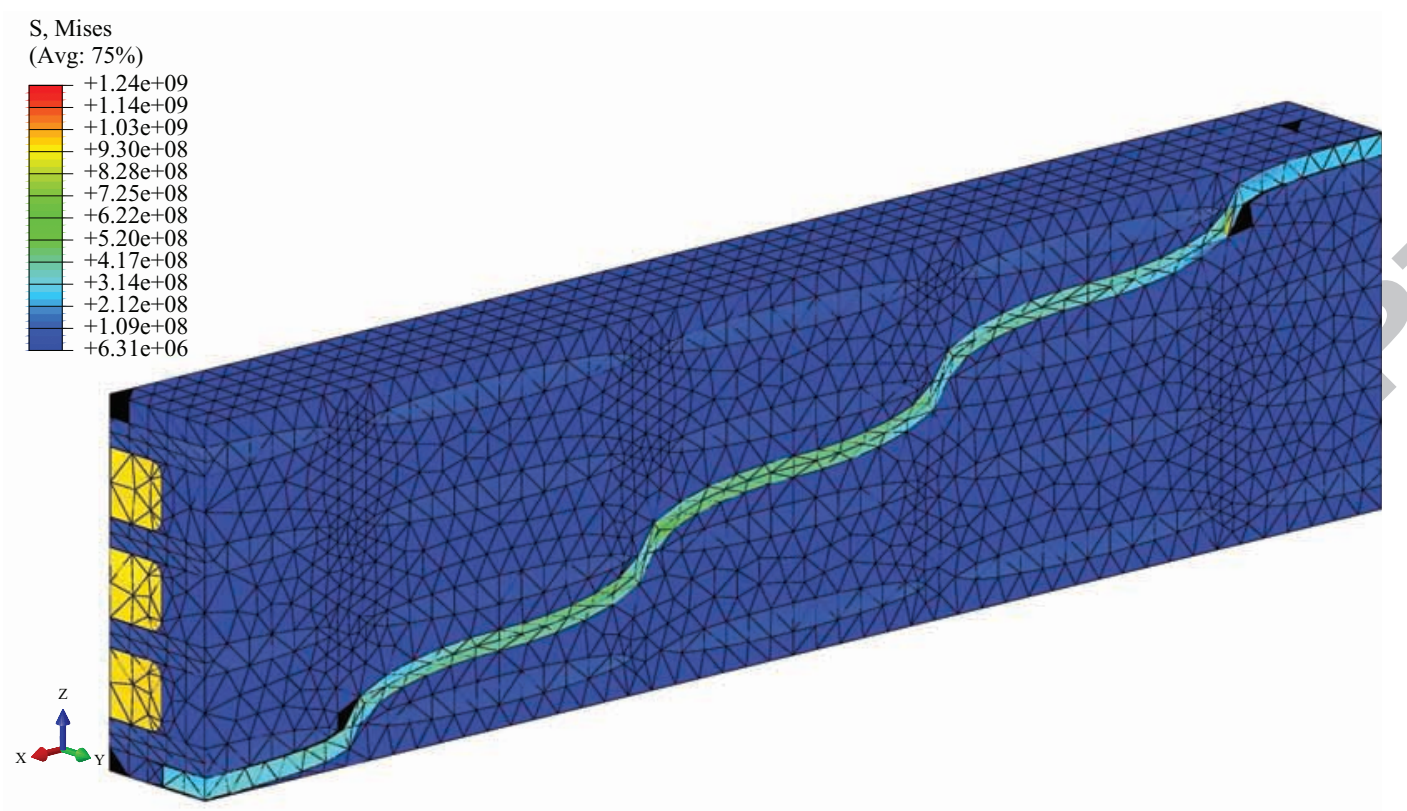

(a) at $323.47 \mathrm{MPa}$

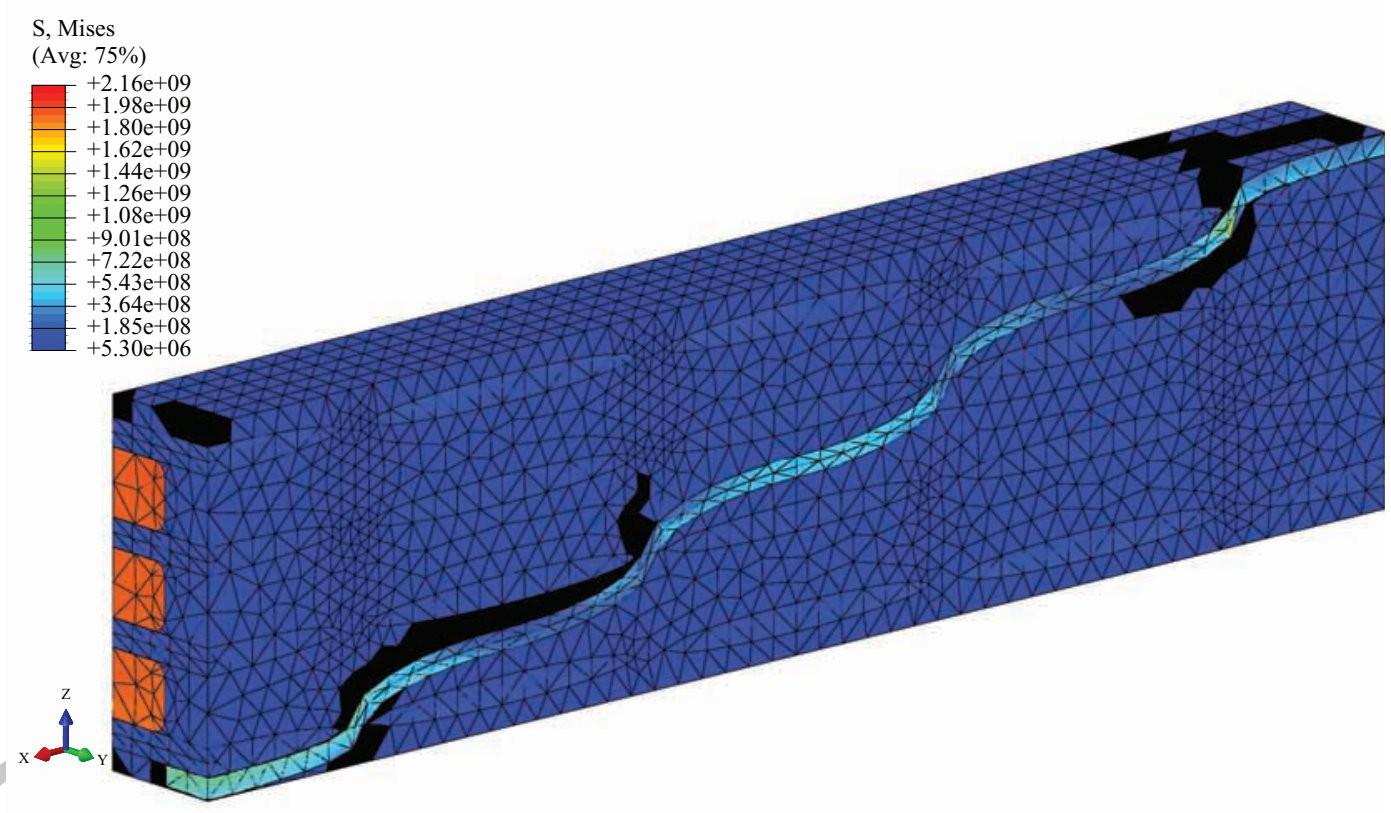

(b) at $622.90 \mathrm{MPa}$

Figure 14: Von-Mises stress distribution and matrix crack propagation in the W-3-Pinho Model. 


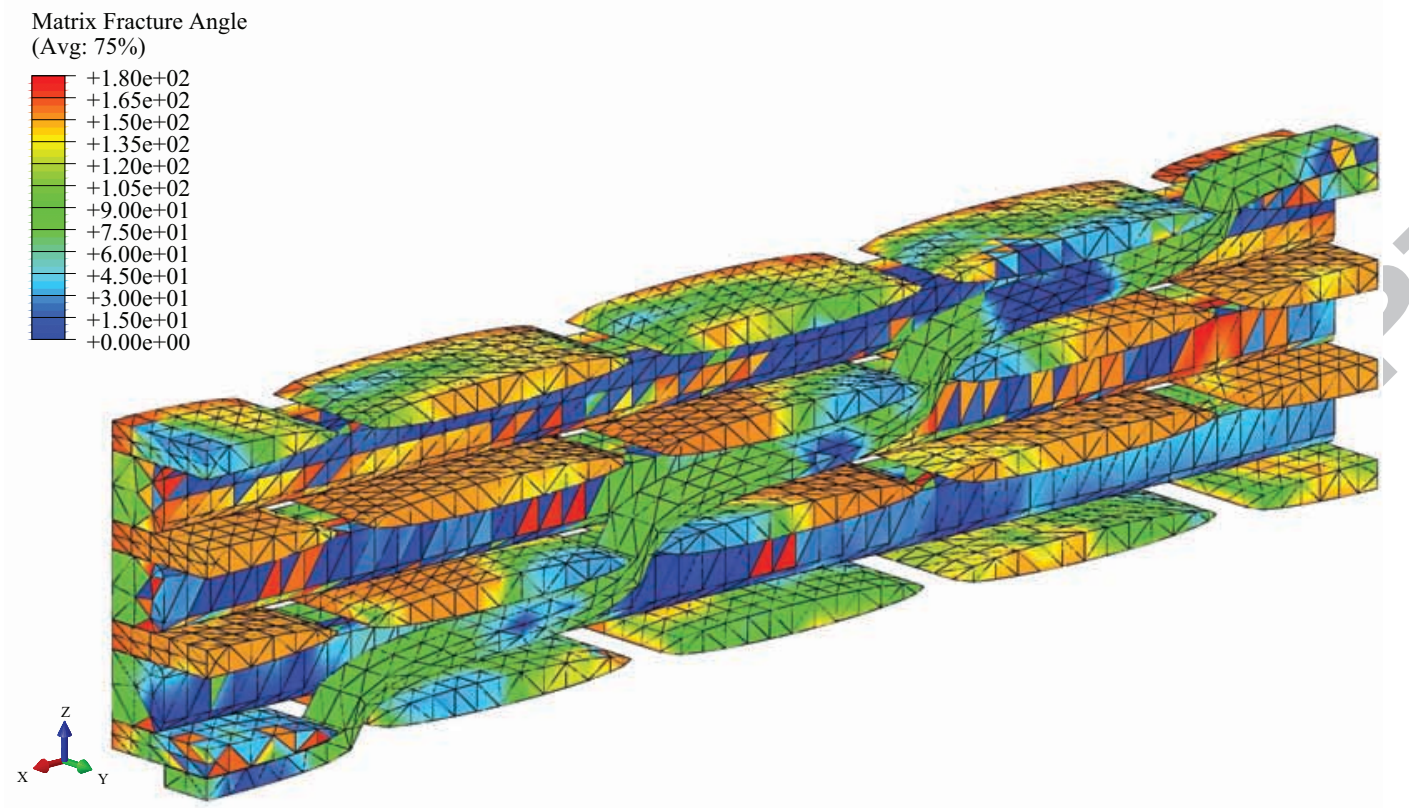

(a)

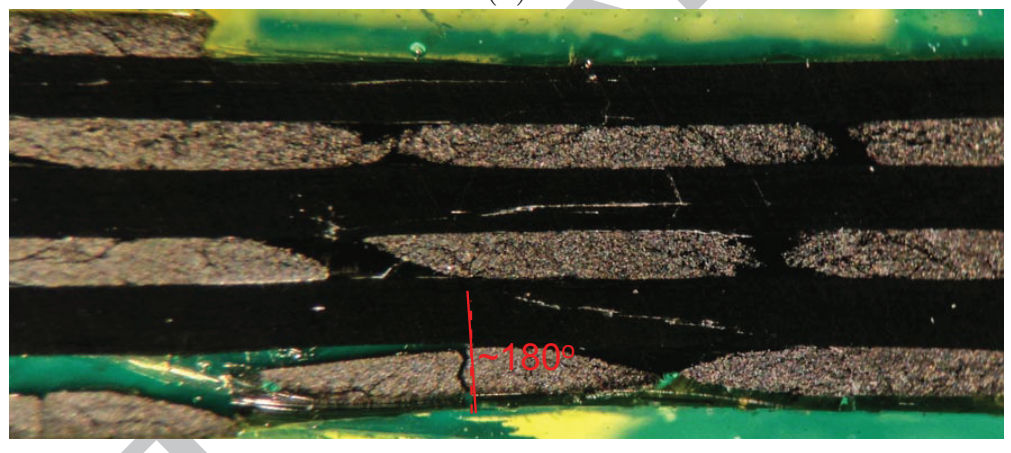

(b)

Figure 15: Intra-tow matrix fracture angle: (a) Distribution of the intra-tow matrix fracture angle $\alpha$ at $1587.36 \mathrm{MPa}$ in the W-3-Pinho Model, (b) Failed section showing fracture angle. 


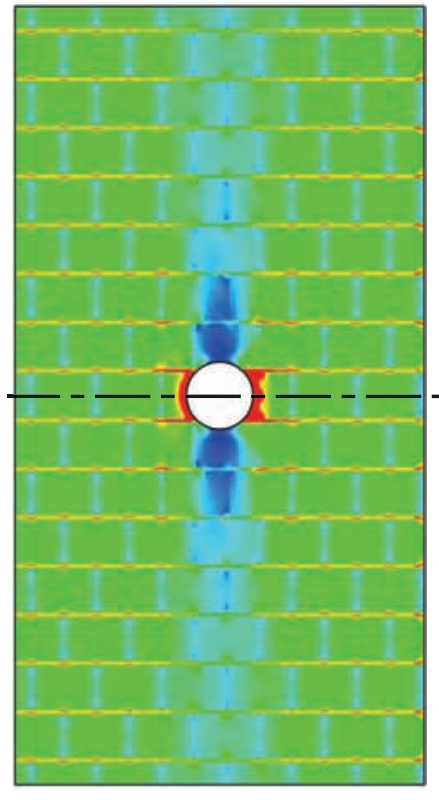

(a)

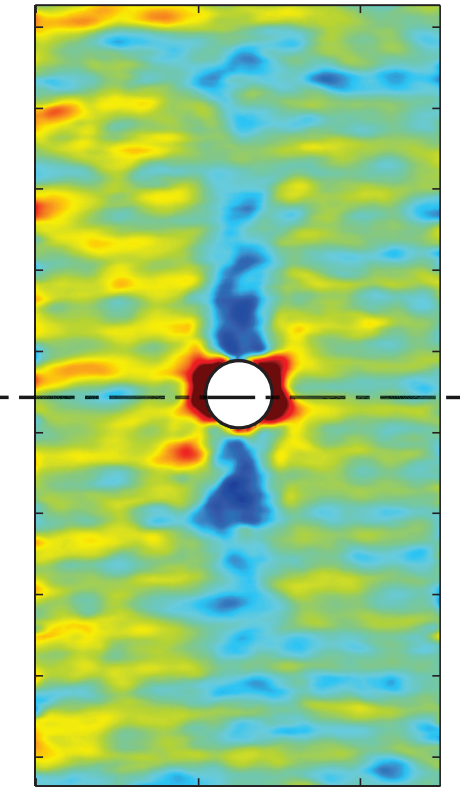

(b)
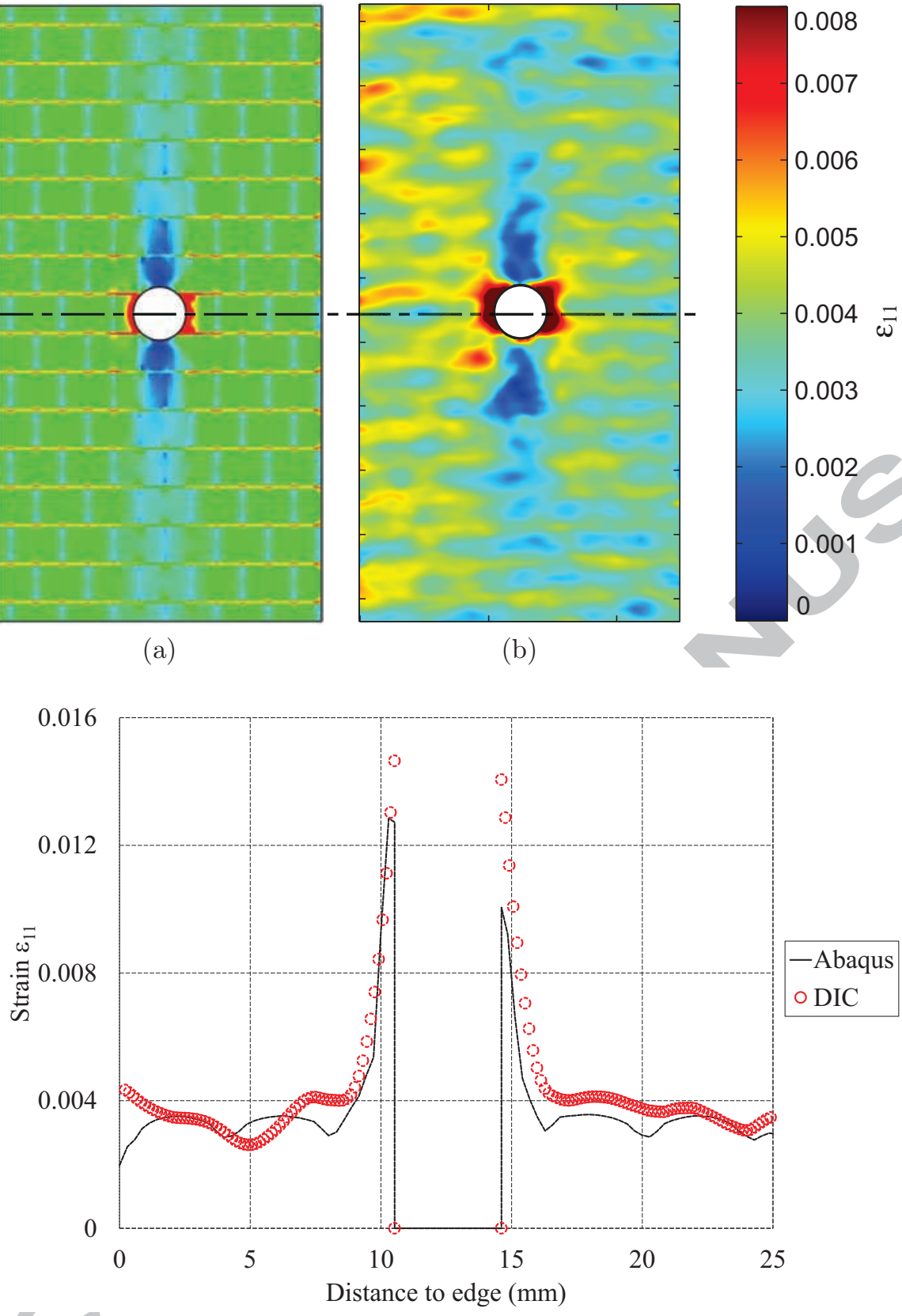

(c)

Figure 16: Longitudinal strain (\%) distribution of W-1-Standard at nominal notch stress of 337 MPa: (a) FEA results, (b) Experimental DIC results, (c) Longitudinal strain along the central line. 


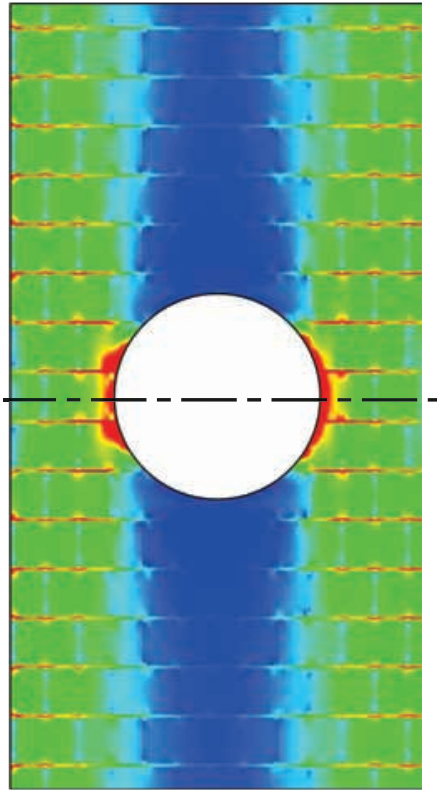

(a)

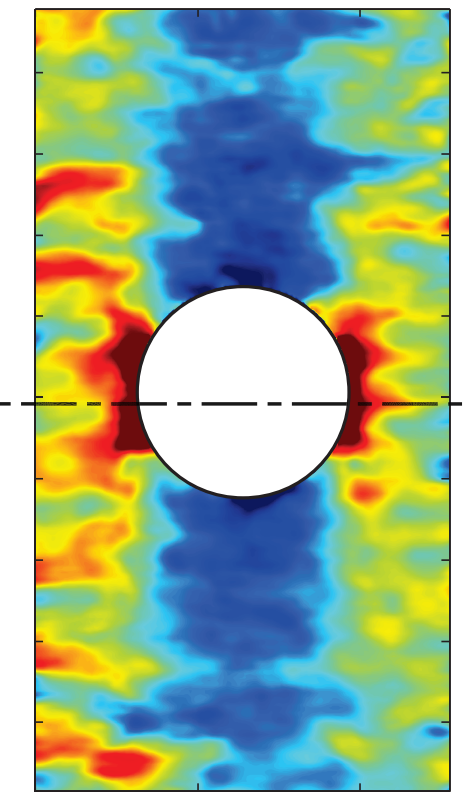

(b)

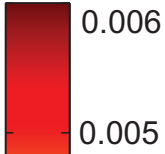

$-0.004$

$-0.003 \bar{\omega}$

0.002

0.001

0
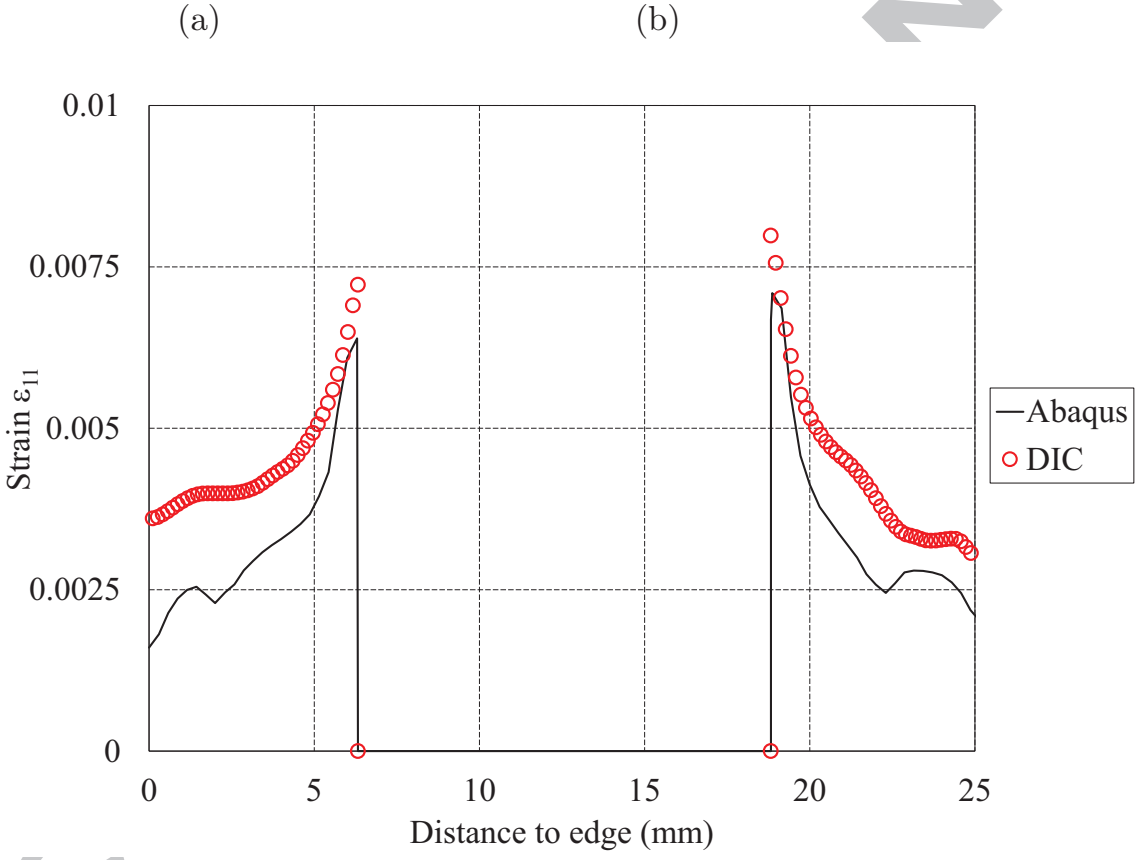

(c)

Figure 17: Longitudinal strain (\%) distribution of W-1-Enlarged at nominal notch stress of 298 MPa: (a) FEA results, (b) Experimental DIC results, (c) Longitudinal strain along the central line. 


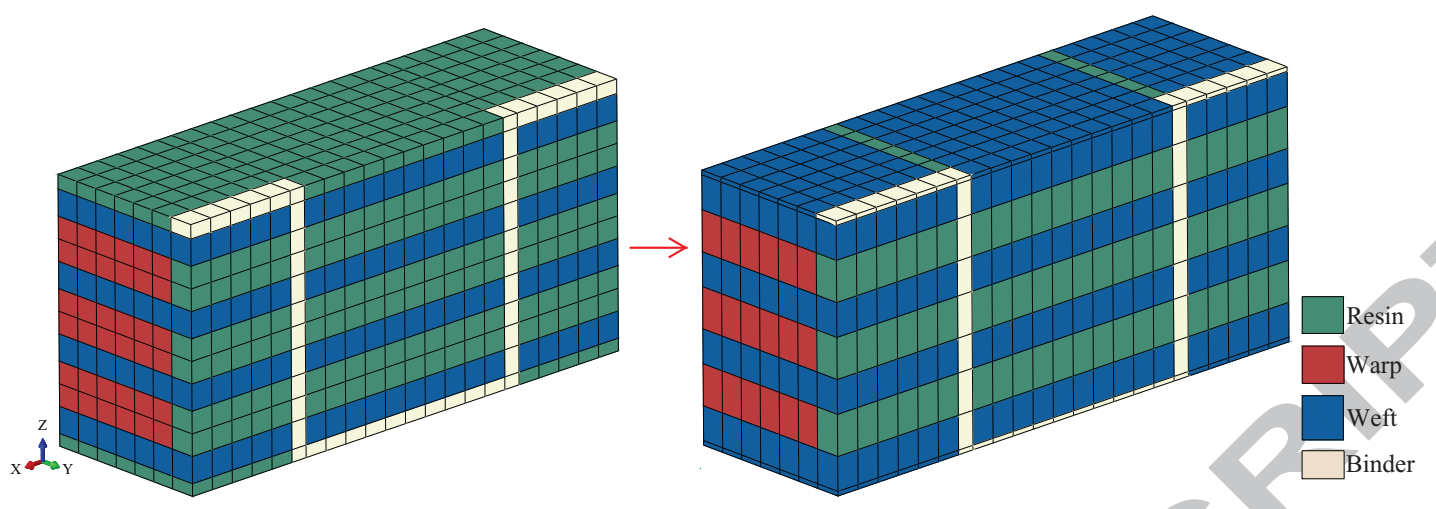

Figure 18: Unit cell of the modified mosaic model.

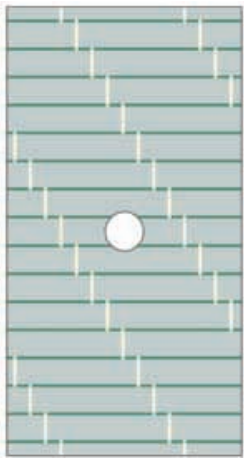

a) Surface

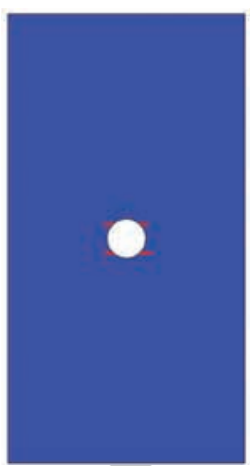

b) $571 \mathrm{MPa}$

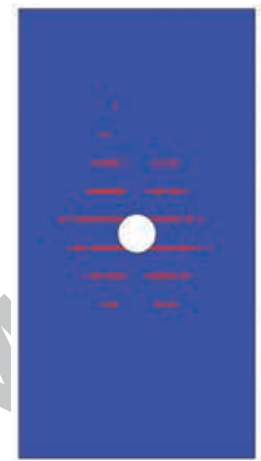

c) $652 \mathrm{MPa}$

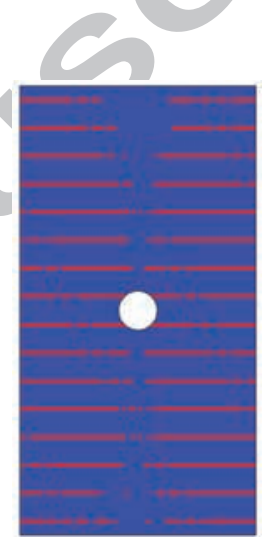

d) $918 \mathrm{MPa}$

Figure 19: Matrix failure progression of W-3 mosaic model (damaged regions are marked in red).

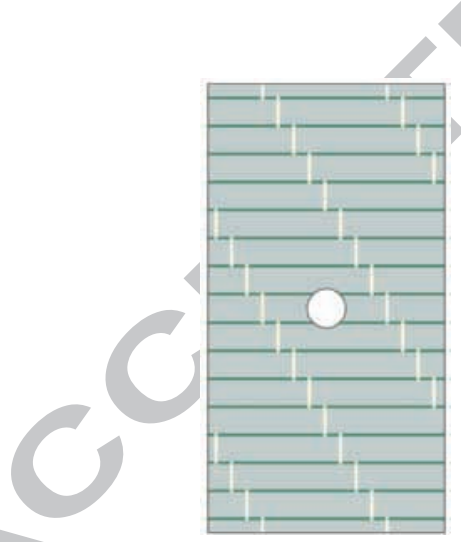

a) Surface

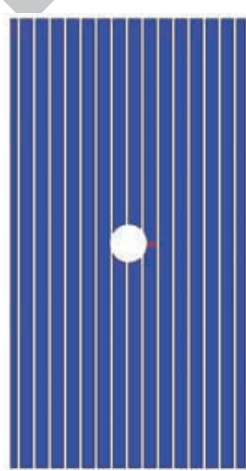

b) $588 \mathrm{MPa}$

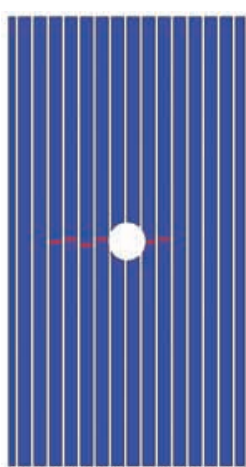

c) $918 \mathrm{MPa}$

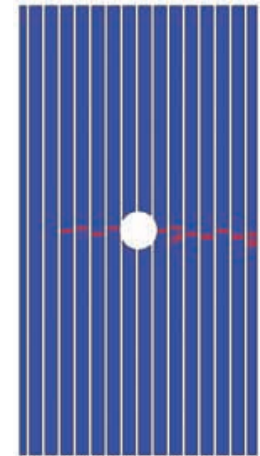

d) $830 \mathrm{MPa}$

Figure 20: Warp tow tensile failure progression of W-3 mosaic model (damaged regions are marked in red). 
Table 2: Fibre volume fraction and thickness of the samples.

\begin{tabular}{lcccccccc}
\hline ID & $V_{f}(\%)$ & CV $(\%)$ & $V_{\text {warp }}(\%)$ & CV $(\%)$ & $V_{\text {weft }}(\%)$ & CV $(\%)$ & t $(\mathrm{mm})$ & CV $(\%)$ \\
\hline W-1 & 49.86 & 1.59 & 27.72 & 4.59 & 21.10 & 5.83 & 2.71 & 3.48 \\
W-3 & 46.01 & 2.57 & 25.66 & 3.02 & 18.09 & 3.18 & 2.77 & 6.11 \\
\hline
\end{tabular}

Table 3: Dimensions of the models.

\begin{tabular}{llccccc}
\hline Weave & Tow & $\mathrm{w}(\mathrm{mm})$ & $\mathrm{h}(\mathrm{mm})$ & spacing $(\mathrm{mm})$ & $\mathrm{UC}$ length $(\mathrm{mm})$ & UC width $(\mathrm{mm})$ \\
\hline \multirow{3}{*}{ W-1 } & Warp & 1.64 & 0.46 & 2.00 & & \\
& Weft & 2.76 & 0.31 & 3.00 & 6.00 & \\
& Binder & 0.33 & 0.12 & 2.00 & & \\
\hline \multirow{2}{*}{ W-3 } & Warp & 1.20 & 0.56 & 2.20 & 24.00 & 2.20 \\
& Weft & 2.70 & 0.23 & 3.00 & \\
& Binder & 0.98 & 0.17 & 2.20 & & \\
\hline
\end{tabular}

Table 4: Elastic properties of the fibre and matrix.

\begin{tabular}{llccccccc}
\hline Tow & Fibre Type & $E_{1}(\mathrm{GPa})$ & $E_{2}(\mathrm{GPa})$ & $\nu_{12}$ & $\nu_{23}$ & $G_{12}(\mathrm{GPa})$ & $G_{23}(\mathrm{GPa})$ & $X_{T}(\mathrm{MPa})$ \\
\hline Warp & IMS60 E13 24K & 290.00 & 28.00 & 0.20 & 0.40 & 8.96 & 10.00 & 5690.00 \\
Weft & HTA 40 E13 6K & 239.00 & 28.00 & 0.20 & 0.40 & 8.96 & 10.00 & 3825.00 \\
Binder $^{\mathrm{W}-1}$ & T300 Toray 1K & 233.00 & 23.10 & 0.20 & 0.40 & 15.00 & 7.00 & 2500.00 \\
Binder $^{\mathrm{W}-3}$ & T33 Toray 3K & 230.00 & 23.10 & 0.20 & 0.40 & 15.00 & 7.00 & 2500.00 \\
Matrix & Gurit Prime20LV & \multicolumn{2}{c}{3.50} & & 0.40 & & 1.25 & 73.00 \\
\hline
\end{tabular}

Table 5: Strength properties of the tows.

\begin{tabular}{clccccccc}
\hline Weave & Tow & $V_{p f}(\%)$ & $X_{T}(\mathrm{MPa})$ & $X_{C}{ }^{1}(\mathrm{MPa})$ & $Y_{T}(\mathrm{MPa})$ & $Y_{C}{ }^{1}(\mathrm{MPa})$ & $S_{12}{ }^{1}(\mathrm{MPa})$ & $S_{23}(\mathrm{MPa})$ \\
\hline \multirow{4}{*}{ W-1 } & Warp & 74.70 & 4268.91 & 1590.00 & 43.92 & 185.00 & 90.00 & 33.79 \\
& Weft & 56.19 & 2181.10 & 1500.00 & 55.14 & 150.00 & 70.00 & 36.18 \\
& Weft & 70.86 & 2731.72 & 1500.00 & 46.80 & 150.00 & 70.00 & 34.40 \\
& Binder & 89.11 & 3153.54 & 950.00 & 63.42 & 125.00 & 97.00 & 31.94 \\
\hline \multirow{2}{*}{ W-3 } & Warp & 85.37 & 4360.32 & 1590.00 & 56.04 & 185.00 & 90.00 & 33.50 \\
& Weft & 83.75 & 1840.41 & 1500.00 & 56.47 & 150.00 & 70.00 & 55.03 \\
& Binder & 82.22 & 2626.01 & 950.00 & 63.64 & 125.00 & 97.00 & 34.61 \\
\hline
\end{tabular}

1 Obtained from [30].

* Surface weft tows. 
Table 6: Predicted tensile strength of unit cell.

\begin{tabular}{llcccc}
\hline Weave & Model & Modulus (GPa) & Experiment (MPa) & Strength (MPa) & Experiment (MPa) \\
\hline \multirow{2}{*}{ W-1 } & Max-Stress & 86.66 & & 1525.36 & 1368.91 \\
& Max-Stress* & 87.64 & 76.75 & 1533.86 & 1589.00 \\
& Pinho & 87.96 & & 1586.88 & 1280.99 \\
& Pinho* & 87.43 & & 1448.35 & 1402.68 \\
W-3 & Max-Stress & 87.06 & & 1483.96 & 142.26 \\
& Max-Stress* & 80.28 & 80.49 & 1429.26 & \\
\hline
\end{tabular}

${ }^{*}$ Model with binder tows replaced by matrix.

Table 7: Predicted tensile modulus of un-notched composites.

\begin{tabular}{ccccc}
\hline Weave & Modulus $(\mathrm{GPa})$ & Experiment $(\mathrm{MPa})$ & Strength $(\mathrm{MPa})$ & Experiment $(\mathrm{MPa})$ \\
\hline $\mathrm{W}-1$ & 86.45 & 76.75 & 1492.67 & 1368.91 \\
\hline $\mathrm{W}-3$ & 80.57 & 80.49 & 1399.64 & 1280.99 \\
\hline
\end{tabular}

Table 8: Predicted open-hole tensile strength using mosaic models.

\begin{tabular}{llrrr}
\hline Weave & Notch & Simulated (MPa) & Experiment (MPa) & Difference (\%) \\
\hline \multirow{2}{*}{ W-1 } & Standard & 782.07 & 1145.71 & -31.74 \\
& Large & 811.66 & 1101.07 & -26.28 \\
\hline \multirow{2}{*}{ W-3 } & Standard & 812.24 & 1265.01 & -35.79 \\
& Large & 795.66 & 1173.50 & -32.20 \\
\hline
\end{tabular}

Table 9: Predicted open-hole tensile strength using mosaic models with modified geometries and modified failure criteria.

\begin{tabular}{llrrr}
\hline Weave & Notch & Strength $(\mathrm{MPa})$ & Difference $(\%)$ & Improvement (\%) \\
\hline \multirow{2}{*}{ W-1 } & Standard & 976.10 & -11.35 & 20.39 \\
& Large & 920.35 & -16.41 & 9.87 \\
\hline \multirow{2}{*}{ W-3 } & Standard & 918.18 & -21.76 & 14.03 \\
& Large & 956.70 & -18.47 & 13.73 \\
\hline
\end{tabular}

